\title{
ZnO Nanostructures for Optoelectronic Applications
}

\author{
Ashok K. Sood1, Zhong Lin Wang', Dennis L. Polla³, Nibir K. Dhar³, \\ Tariq Manzur ${ }^{4}$ and A.F.M. Anwar ${ }^{5}$ \\ ${ }_{1}^{1}$ Magnolia Optical Technologies Inc, 52-B Cummings Park, Suite 314, \\ Woburn, MA 01801 \\ ${ }^{2}$ School of Materials Science and Engineering, Georgia Institute of Technology, \\ 771 Ferst Drive, Atlanta, GA 30332 \\ ${ }^{3}$ DARPA /MTO, 3701 North Fairfax Drive, Arlington, VA 22203 \\ ${ }^{4}$ Naval Underwater Warfare Center, 1176 Howell Street, Newport, RI 02841 \\ ${ }^{5}$ Department of Electrical Engineering, University of Connecticut, Storrs, CT 06269
}

U.S.A.

\section{Introduction}

$\mathrm{ZnO}$ is a unique material that exhibits both semiconducting and piezoelectric properties. $\mathrm{ZnO}$ is a unique material that exhibits both Semi conducting and piezoelectric properties. $\mathrm{ZnO}$ devices have been demonstrated for applications in piezoelectric pressure sensors and Pyroelectric infrared detectors [1] and Spintronic devices [2]. More recently, there has been significant effort underway for design and development of $\mathrm{ZnO}$ nanostructures such as $\mathrm{ZnO}$ nanowires for a variety of applications [3-7].

The $\mathrm{ZnO}$ nanostructures can be implemented in Optoelectronic, Sensors, Transducers and Biomedical applications [1, 2, 3, 4]. Use of these nanostructures, will allow building of Nanoscale nanosensors, nanocantilevers, field-effect transistors and nanoresonators for a variety of Military, Homeland Security and Commercial Applications. Due to the advancement of materials technology over the past decade, wide-band gap semiconductors such as $\mathrm{SiC}, \mathrm{GaN}$ and $\mathrm{ZnO}$ have emerged as $\mathrm{UV}$ sensitive materials that have applications for UV lasers, UV Photodetector, switches, Bio-Sensors and solar cells.

$\mathrm{ZnO}$ wide-band gap semiconductor is promising for sensor applications in the UV range. The band-gap is $3.2 \mathrm{eV}$ for $\mathrm{ZnO}$. Therefore, $\mathrm{GaN}$ and $\mathrm{ZnO}$, as well as $\mathrm{SiC}$ are potentially good materials to cover the UV spectral band $(240-280 \mathrm{~nm})$, when solar radiation is completely absorbed by the ozone layer of the earth atmosphere, so the background of solar radiation at the earth surface is essentially zero.

$\mathrm{ZnO}$ is transparent to visible light and can be made highly conductive by doping. $\mathrm{ZnO}$ is a versatile functional material that has a diverse group of growth morphologies. These growth morphologies have been demonstrated for nanowires (1), nanobelts (2), nanocages (3), nanocombs (4), nanosprings (5), nanorings (6), nanohelixes (7). The objective of this chapter is to review the unique $\mathrm{ZnO}$ nanostructure devices and characterized for optoelectronic applications. 


\section{Crystal structure of $\mathrm{ZnO}$ and its polar surfaces}

Table 1 lists the basic physical properties of bulk ZnO. It is worth noting that as the dimension of the semiconductor materials continuously shrinks down to nanometer or even smaller scale, some of their physical properties undergo changes known as the "quantum size effects" [8]. For example, quantum confinement increases the band gap energy of quasione-dimensional (Q1D) ZnO, which has been confirmed by photoluminescence [8].

Bandgap of $\mathrm{ZnO}$ nanoparticles also demonstrates such size dependence. Understanding the fundamental physical properties is crucial to the rational design of functional devices. Investigation of the properties of individual $\mathrm{ZnO}$ nanostructures is essential for developing their potential as the building blocks for future nanoscale devices.

\begin{tabular}{|l|l|}
\hline \multicolumn{1}{|c|}{ Properties } & \\
\hline Lattice constants $(\mathrm{T}=300 \mathrm{~K})$ & \\
$\mathrm{a}_{0}$ & $0.32469 \mathrm{~nm}$ \\
$\mathrm{c}_{0}$ & $0.52069 \mathrm{~nm}$ \\
Density & $5.606 \mathrm{~g} / \mathrm{cm}^{3}$ \\
Melting point & $2248 \mathrm{~K}$ \\
Relative dielectric constant & 8.66 \\
Gap Energy & $3.4 \mathrm{eV}$, direct \\
Intrinsic carrier concentration & $<10^{6} \mathrm{~cm}^{-3}$ \\
Exciton binding Energy & $60 \mathrm{meV}$ \\
Electron effective mass & 0.24 \\
Electron mobility $(\mathrm{T}=300 \mathrm{~K})$ & $200 \mathrm{~cm}^{2} / \mathrm{V} \mathrm{s}$ \\
Hole effective mass & 0.59 \\
Hole mobility $(\mathrm{T}=300 \mathrm{~K})$ & $5-50 \mathrm{~cm}^{2} / \mathrm{V} \mathrm{s}$ \\
\hline
\end{tabular}

Table 1. Physical properties of wurtzite ZnO [Fan et al; Ref 8]

Zinc oxide has a hexagonal structure (space group $P 6_{3} m c$ ) with lattice parameters $a=0.3296$, and $c=0.52065 \mathrm{~nm}$. The structure of $\mathrm{ZnO}$ can be simply described as a number of alternating planes composed of tetrahedral coordinated $\mathrm{O}^{2-}$ and $\mathrm{Zn}^{2+}$ ions, stacked alternatively along the $c$-axis (Figure 1a). The tetrahedral coordination in $\mathrm{ZnO}$ results in noncentral symmetric structure and piezoelectricity. Another important characteristic of $\mathrm{ZnO}$ is the polar surfaces. The most common polar surface is the basal plane. The oppositely charged ions produce positively charged Zn-(0001) and negatively charged O-(000 $\overline{1})$ polar surfaces (Figure $1 \mathrm{~b}$ ), resulting in a normal dipole moment and spontaneous polarization along the $c$-axis.

Another polar surface is the $\{01 \overline{1} 1\}$. By projecting the structure along [1 $\overline{2} 10]$, as shown in Figure $1 \mathrm{~b}$, beside the most typical $\pm(0001)$ polar surfaces that are terminated with $\mathrm{Zn}$ and oxygen, respectively, $\pm(10 \overline{1} 1)$ and $\pm(10 \overline{1} \overline{1})$ are also polar surfaces. The $\{10 \overline{1} 1\}$ type surfaces are not common for $\mathrm{ZnO}$, but they have been observed in a nanohelical structure found recently [9]. The charges on the polar surfaces are ionic charges, which are nontransferable and non-flowable. Because the interaction energy among the charges depends 
on the distribution of the charges, the structure is arranged in such a configuration to minimize the electrostatic energy. This is the main driving force for growing the polar surface dominated nanostructures.

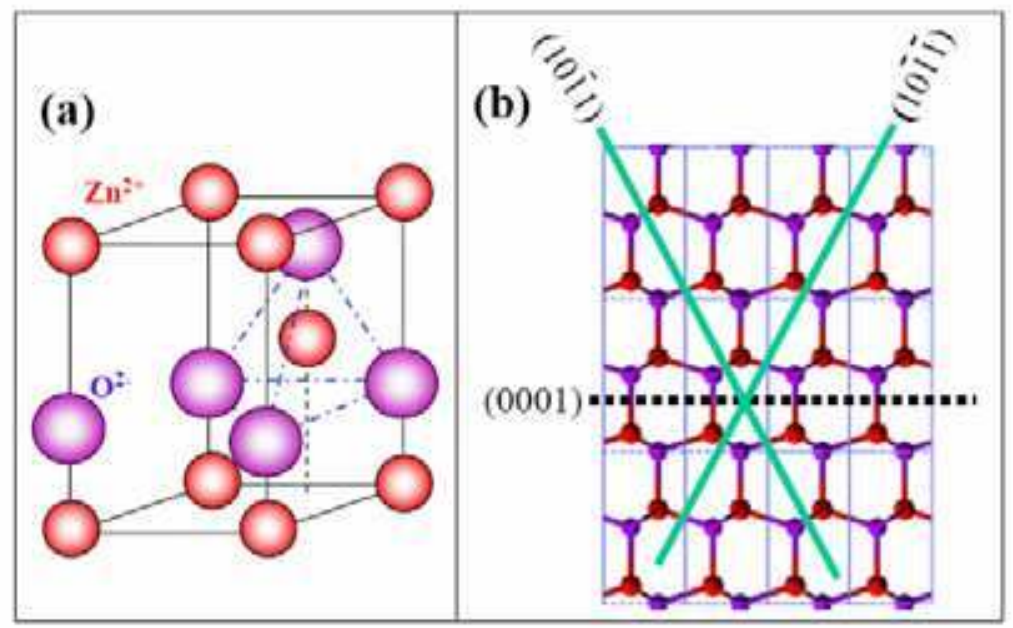

Fig. 1. (a) Wurtzite structure model of $\mathrm{ZnO}$. The tetrahedral coordination of $\mathrm{Zn}-\mathrm{O}$ is shown. (b) The structure model of $\mathrm{ZnO}$ projected along [2 $\overline{1} \overline{1} 0]$, displaying the $\pm(0001), \pm(01 \overline{1} \overline{1})$ and $\pm(01 \overline{1} 1)$ polar surfaces

\section{Growth of $\mathrm{ZnO}$ nanostructures}

Growth of $\mathrm{ZnO}$ nanostructures has been carried out by several groups using the techniques that are still being developed for their reliability and throughput. These approaches are listed in three broad categories. These include:

1. Vapor Phase Deposition Technique ( Solid-Vapor Process) [10]

2. Chemical Synthesis Method [10]

3. Induction Heating Method [11]

4. Metal-Organic Chemical Vapor Deposition (MOCVD) [12,13]

There are several processing parameters such as temperature, pressure, carrier gas (including gas species and its flow rate), substrate and evaporation period, which can be controlled and need to be selected properly before and/or during the thermal vaporization [10]. The source temperature selection mainly depends on the volatility of the source material(s). Usually, it is slightly lower than the melting point of the source material. The pressure is determined according to the evaporation rate or vapor pressure of the source material(s). The schematic representation of the Vapor Phase Deposition technique is shown in figure 2 .

The substrate temperature usually drops with the distance of its location from the position of the source material(s). The local temperature determines the type of product that will be obtained. It is also noted that the thermal evaporation process is very sensitive to the concentration of oxygen in the growth system. Oxygen influences not only the volatility of 
the source material(s) and the stoichiometry of the vapor phase, but also the formation of the product(s).

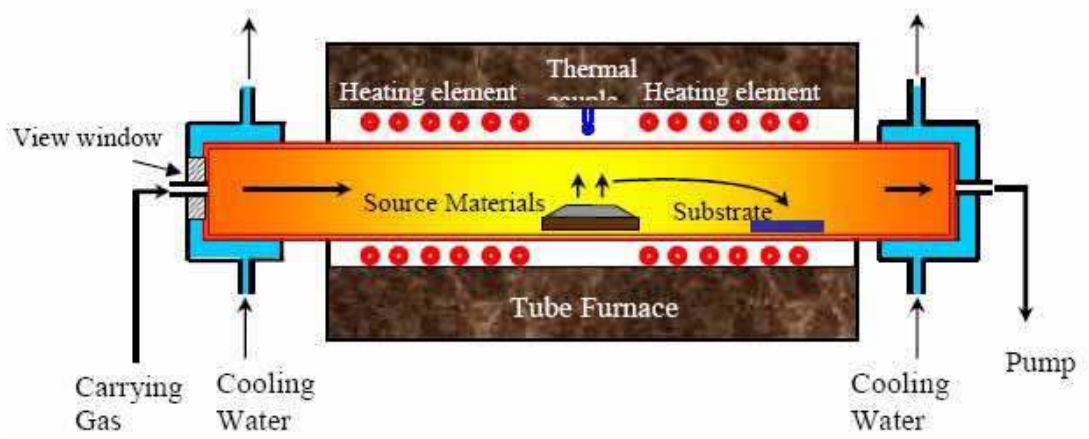

Fig. 2. A schematic diagram of the experimental apparatus for growth of oxides nanostructures by the solid-vapor phase process [Wang et al; Ref 10]

The Second Growth approach for $\mathrm{ZnO}$ nanowires uses the chemical synthesis method [10]. This is a hydrothermal method, where the growth procedure for growth of $\mathrm{ZnO}$ nanowires is as follows:1). Suspend the surface modified substrate in a Pyrex glass bottle filled with an equal molar aqueous solution of zinc nitrate hydrate ( $\mathrm{Zn}(\mathrm{NO} 3) 2.6 \mathrm{H} 2 \mathrm{O})$ and hexamethylenetetramine (C6H12N4) at temperatures between 60-90 C. 2). The temperature, $\mathrm{PH}$, solution concentration, reaction time (a range of 1-72 hours) and substrate surface status were optimized for growing Nanowire arrays with controlled dimensions and orientation. $3)$. after completion of the reaction, the substrates were removed from the solution, and rinsed by de-ionized water, and dried in air at $65 \mathrm{C}$.

The third approach uses the inductive heating assisted fast synthesis of $\mathrm{ZnO}$ nanowires using $\mathrm{ZnO} /$ graphite solid source powder in a room temperature environment [13]. The internal heat generation induced by the alternating magnetic field at the synthesis specimen enables the fast temperature transition for $\mathrm{ZnO}$ nanowire growth, with a synthesis time less than 5 min compared to conventional methods. Furthermore, this demonstration illustrates the feasibility of a simple and fast nanoscale synthesis using inductive heating for nanomaterials synthesis [13].

Figure $3 \mathrm{a}$ shows the schematic illustration for the $\mathrm{ZnO}$ nanowire synthesis setup. The synthesis specimen is placed inside a quartz tube underneath the center of an eight-turn inductive coil with a pitch of $3.25 \mathrm{~mm}$ and an inner/outer diameter of $12.7 / 19.2 \mathrm{~mm}$. The distance between the coil base and the synthesis specimen is $-6 \mathrm{~mm}$.

The cross sectional view of the synthesis specimen, including a nickel coated heating chip, source powder, and growth chip inside a ceramic boat, is shown in Figure $3 \mathrm{~b}$. When an alternating current is applied in the coil, an alternating magnetic field is generated, which induces eddy currents in the nickel layer and provides rapid Joule heating for nanowire synthesis. Analytically, one can derive each coil's magnetic field intensity generated at any point with a scalar distance of $d$ with respect to the coil loop center from Biot-Savart's law [Lin et al 2007; Ref 11]. 

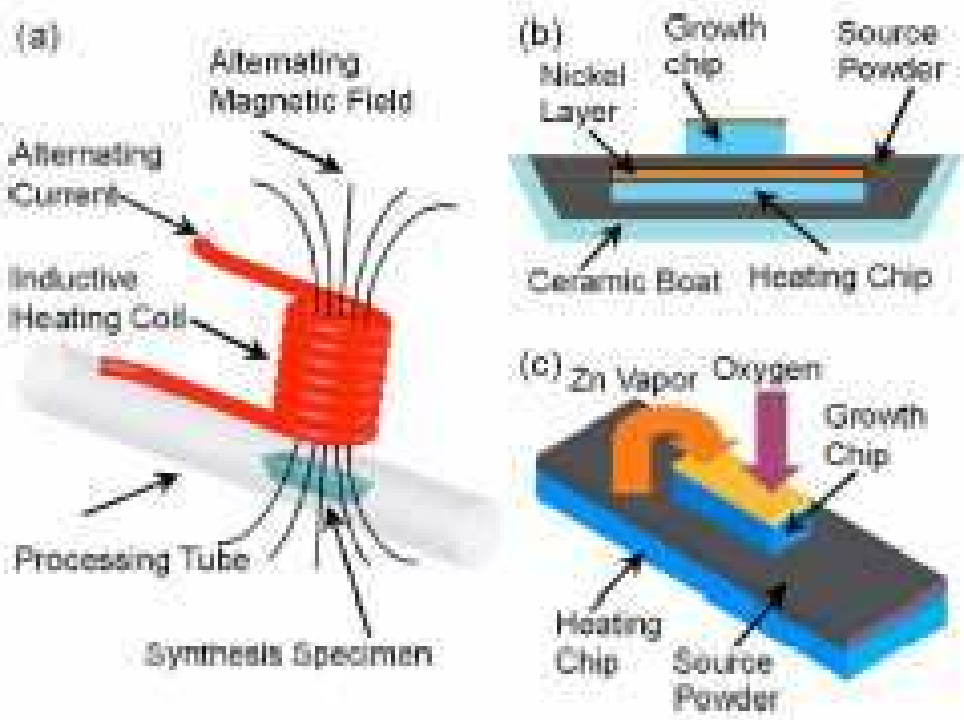

Fig. 3. Schematic illustration for $\mathrm{ZnO}$ nanowire synthesis setup using induction heating method (a). Cross sectional view of the synthesis specimen consisting of a heating chip, source powder, and growth chips inside a ceramic boat (b). Three-dimensional sketch of the heating chip/source powder/growth (c) [Lin et.al; Ref 11]

Several groups are have used Metal-Organic Chemical Vapor Deposition (MOCVD) successfully to grow $\mathrm{ZnO}$ nanostructures and have shown good results [12, 13]. Further work is underway to develop this technology for oriented $\mathrm{ZnO}$ nanowires for optoelectronic applications.

\section{Oriented nanostructures growth}

For the first two growth approaches, selectively patterned substrates have been used to control the density and selectivity of the aligned growth. The patterned materials can be catalysts $(\mathrm{Au}, \mathrm{Ni}$, etc.). The patternings methods are Electron-beam Lithography and Focused ion beam Microscopy.

Figure 4 presents a standard process for E-beam lithography. First step is to spin-coat Ebeam resist PMMA of desired thickness layer on the substrate, and then using electron beam to selectively expose the patterned area of PMMA coating. Next step is to develop the exposed pattern using MIBK solution. After this step, the PMMA coating on the Si substrate is left with a pattern, which is subsequently filled by metal deposition, and the remaining PMMA can be lifted off in acetone.

This patterned substrate can be used for growth of $\mathrm{ZnO}$ nanowires. They are currently developing the lift-off process to fabricate the substrates. Once the process is refined on Silicon substrates, it can be further implemented on other substrates [10].

Figure 5 presents Au-pattern on Si substrate. We have recently achieved the Au-pattern using E-beam lithography. The patterned gold dot array is 2 um in diameter, 2 um in spacing, and $200 \mathrm{~nm}$ in height. 
a)

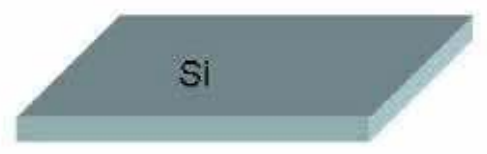

\section{$\left\{\begin{array}{l}\text { Spin coating of } \\ \text { PMMA }\end{array}\right.$}

b)

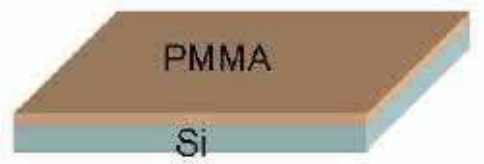

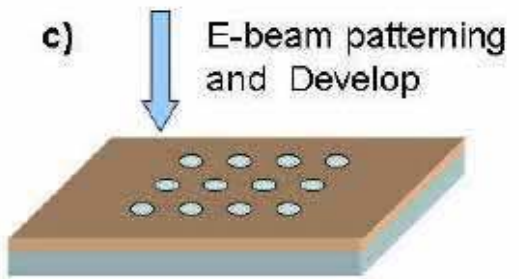

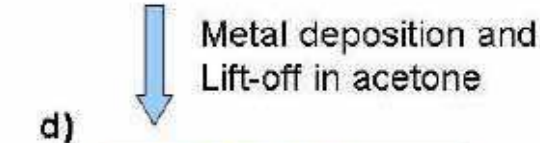

d)

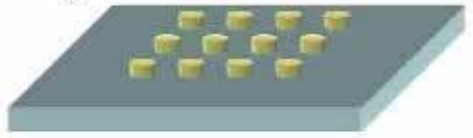

Fig. 4. E-beam Lithography Process Flow for growth of ZnO Nanowires [Wang et al; Ref 10]

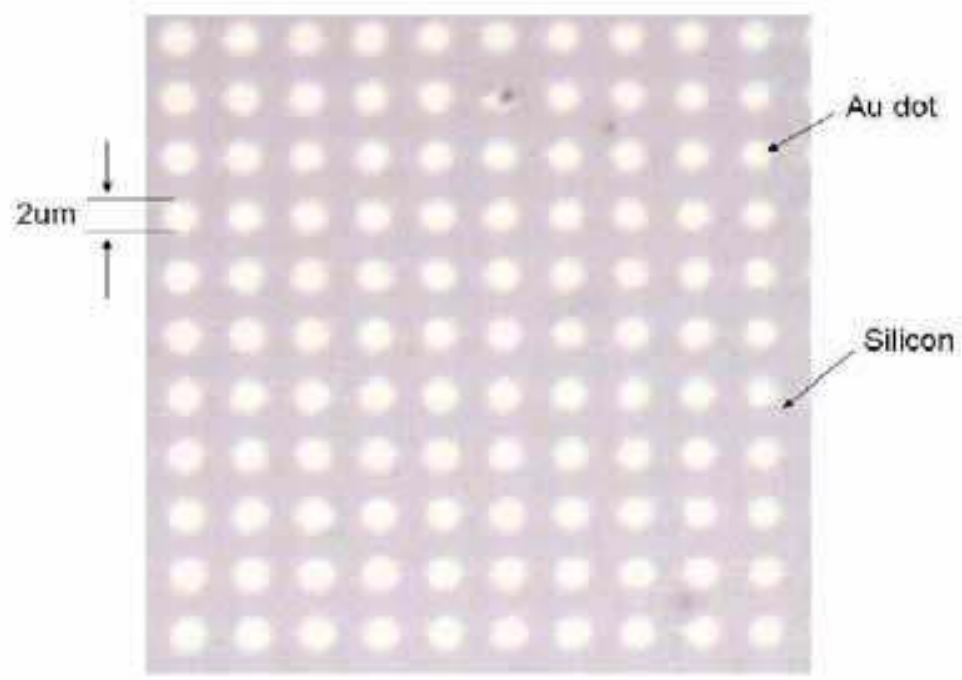

Fig. 5. Au Pattern on Silicon substrate with 20 micron size [Wang et al; Ref 10]

The hydrothermal synthesis method has been very successful in terms of synthesizing large scale nanowires arrays on Silicon substrates. As shown in figure $6 a$ is a side view SEM image of the as grown $\mathrm{ZnO}$ nanowires arrays on Au-coated Si substrate, the alignment is very good. The zoom-in image in the inset displayed the dimensions of the grown nanowire, $\sim 200 \mathrm{~nm}$ in diameter, $\sim 5 \mathrm{um}$ in lengths. 
Figure $6 \mathrm{~b}$ shows the top view of aligned nanowire arrays; the top-right inset enlarged picture clearly illustrated the hexagonal cross-section of the nanowires. The bottom-right CCD image is showing a 2-inch diameter sized area of nanowires arrays grown on an Aucoated substrate.

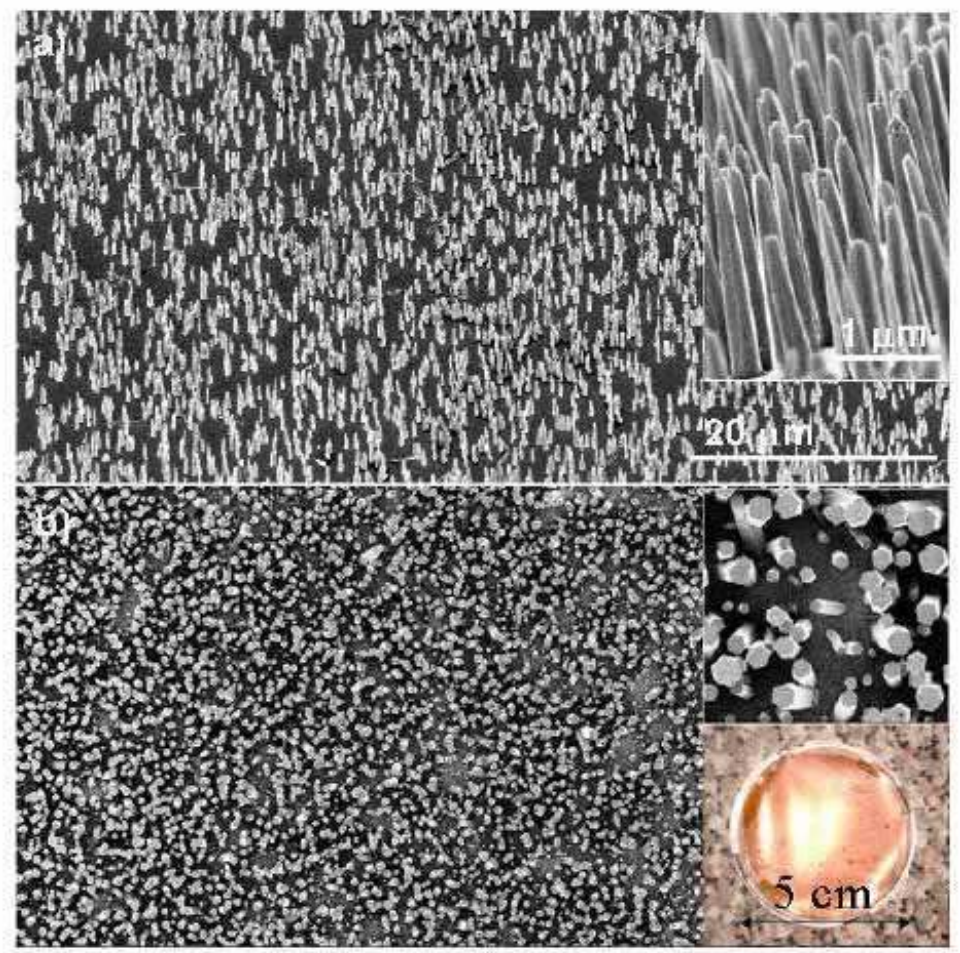

Fig. 6. ZnO Nanowires grown on Silicon Substrate [Wang et al; Ref 10]

Besides $\mathrm{Au}$, they have also evaluated the $\mathrm{ZnO}$ seeds for promoting growth of $\mathrm{ZnO}$ nanowires using hydrothermal synthesis. As shown in figure 6a, a low-magnification SEM image showing the growth of $\mathrm{ZnO}$ nanowires on $\mathrm{ZnO}$ seeds coated ( $30 \mathrm{~nm}$ in thickness) PMMA film. The wavy feature is due to the non-uniform PMMA coating surface. The enlarged top view was revealed in figure $6 \mathrm{~b}$, witnessing the randomly grown nanowires with sharp tips $\sim 20 \mathrm{~nm}$ in diameter. The EDS analysis in figures $6 \mathrm{c}-\mathrm{d}$ revealed the main composition of $\mathrm{ZnO}$ with some impurities. They have identified the impurity to be Chromium (Figure 6d).

Density controls of nanowires growth are also being studied as an important parameter for the UV detector and Sensor application. As shown in figure 7, a typical dispersive nanowires array on Au-coated Si substrate. The wire diameter is about 1-2 um (figure $7 \mathrm{~b}$ ), the length can be as long as $30 \mathrm{um}$, and the spacing in between nanowires are $\sim 5-15 \mathrm{um}$. Figure $7 \mathrm{c}$ revealed the additional growth of nanoscale $\mathrm{ZnO}$ dots on the $\mathrm{Si}$ substrate corresponding to the densely distributed nanodots in figure $7 \mathrm{~b}$, which might be the seeds (nuclei) of $\mathrm{ZnO}$ nanowires growth. 

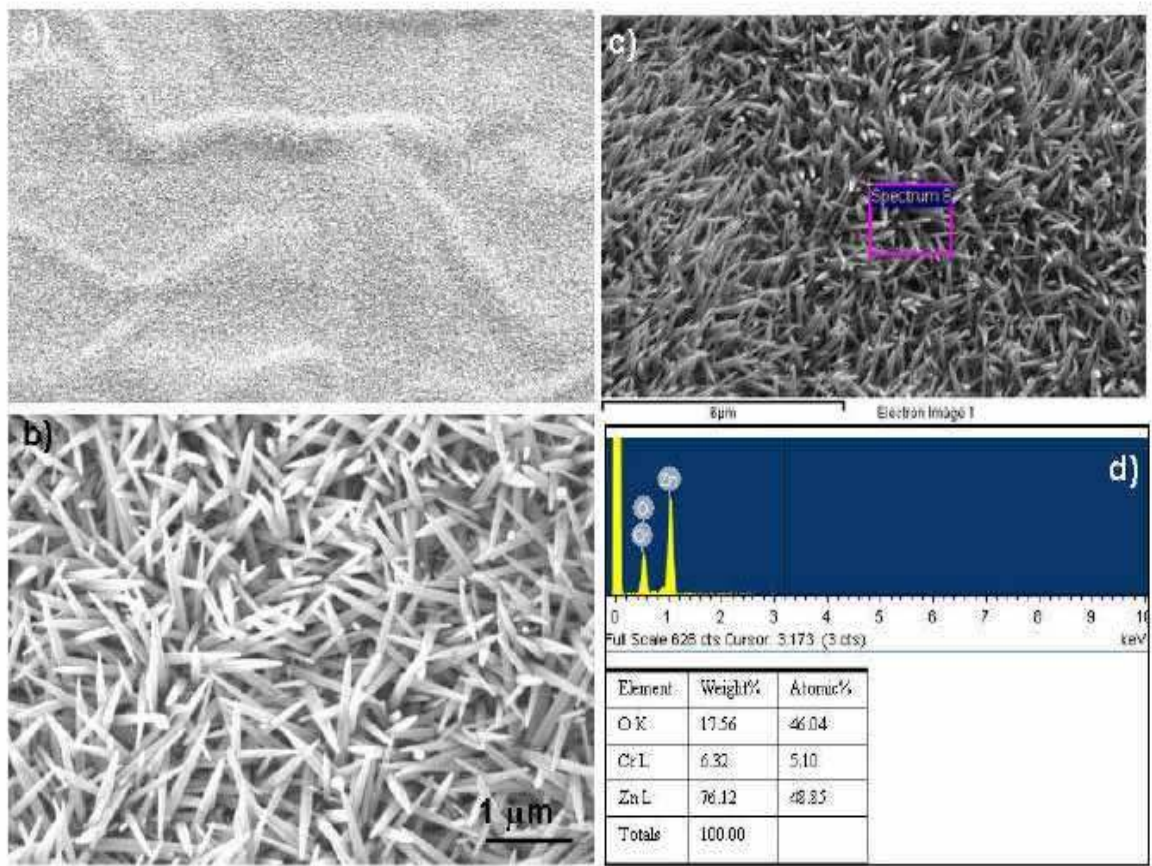

Fig. 7. ZnO nanowire growth on $\mathrm{ZnO}$ coated substrates [Wang et al; Ref 10]
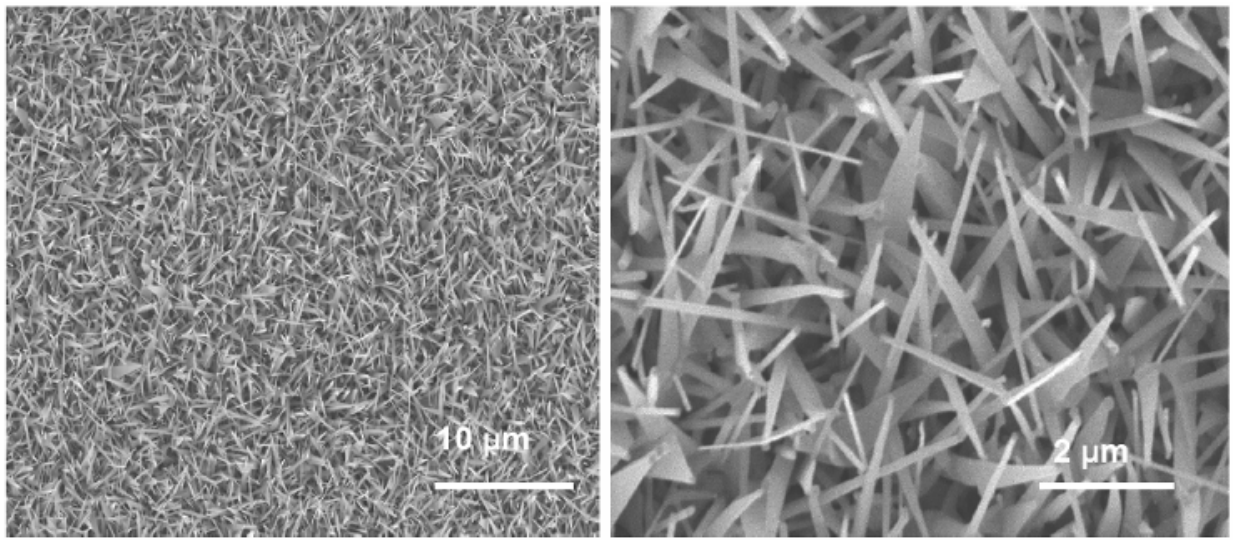

Fig. 8. ZnO nanowires grown on $\mathrm{SiC}$ (0001) substrates with $2 \mathrm{~nm}$ Au at $960 \mathrm{C}$ [Wang et al; Ref 10]

They have also evaluated growth of $\mathrm{ZnO}$ nanowires on $\mathrm{SiC}$ substrates. $\mathrm{SiC}$ being a wide bandgap semiconductor can be used for active device fabrication. For this effort, we have used $\mathrm{SiC}$ (0001) substrates. We have used thermal evaporation method using $\mathrm{ZnO}$ and $\mathrm{C}$ as source material. Au, 2-4 nm thick was used as a catalyst for the growth. We also used Argon 
and Oxygen as the carrier gases. Figure 8 presents the $\mathrm{ZnO}$ nanowires and nanosheets on $\mathrm{SiC}$ (0001) coated with $2 \mathrm{~nm}$ gold. The growth was carried out at $960 \mathrm{C}$, using Argon and Oxygen. The growth was carried out for 30 minutes.

The results in figures 8 show their attempts to grow the $\mathrm{ZnO}$ nanowires. The process is still being optimized for oriented growth with different growth temperatures and gas flow along with various catalysts. These nanowires show that high density growth of $\mathrm{ZnO}$ nanowires is quite feasible and need further growth optimization for oriented growth. Figure 9 presents the TEM characterization of $\mathrm{ZnO}$ nanowires grown on $\mathrm{SiC}(0001)$ substrate with Au catalyst. This can open a variety of device configurations for optical and other applications using ZnO nanowires.

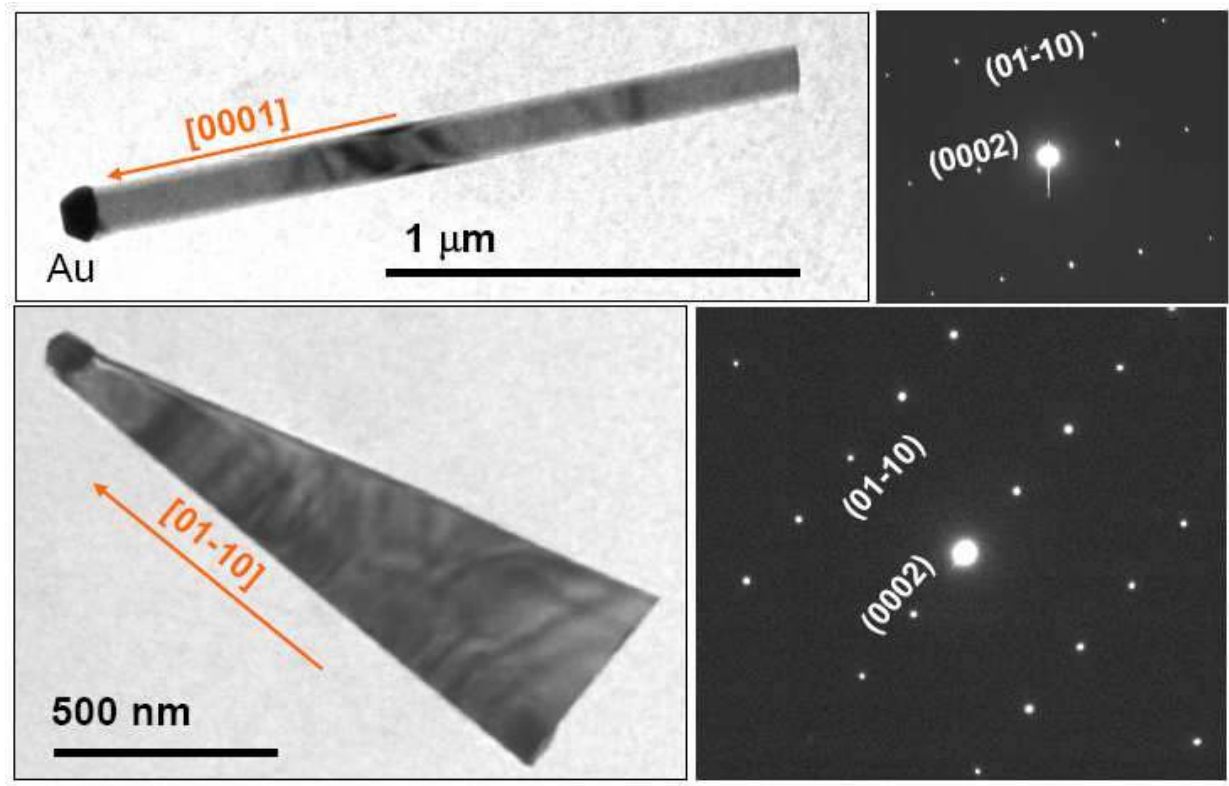

Fig. 9. TEM characterization of $\mathrm{ZnO}$ nanowires grown on $\mathrm{SiC}(0001)$ substrates shown in figure 8.The orientation of $\mathrm{ZnO}$ nanowires with two orientations are illustrated [ Wang et al; Ref 10]

Their work has shown that $\mathrm{Sn}$ can also be an effective catalyst for growing $\mathrm{ZnO}$ nanorods [14]. Using the epitaxial growth of $\mathrm{ZnO}$ nanorods on $\mathrm{ZnO}$ crystal, aligned nanorods have been grown as shown in figure 10. In this case, the growth direction of the nanorods is led by the Sn catalyst and the epitaxial orientation is defined by the substrate that determines the aligned growth. The nanorods are also aligned in orientation because they tend to take the least mismatch orientation on the substrate, to reduce the interface mismatch energy.

The choice of substrate is important for the epitaxial growth. One must consider the crystallographic structure as well as the surfaces to be used for the growth. We have found recently that the atomic termination and charge status of the substrate can strongly affect the morphology of the grown nanorods [14]. The nanorods growing out of $\mathrm{Zn}$-terminated (0001) $\mathrm{ZnO}$ substrates are very different from those grown out of the oxygen-terminated $(000 \overline{1})$ $\mathrm{ZnO}$ substrates although the same type of Sn catalyst was used. 


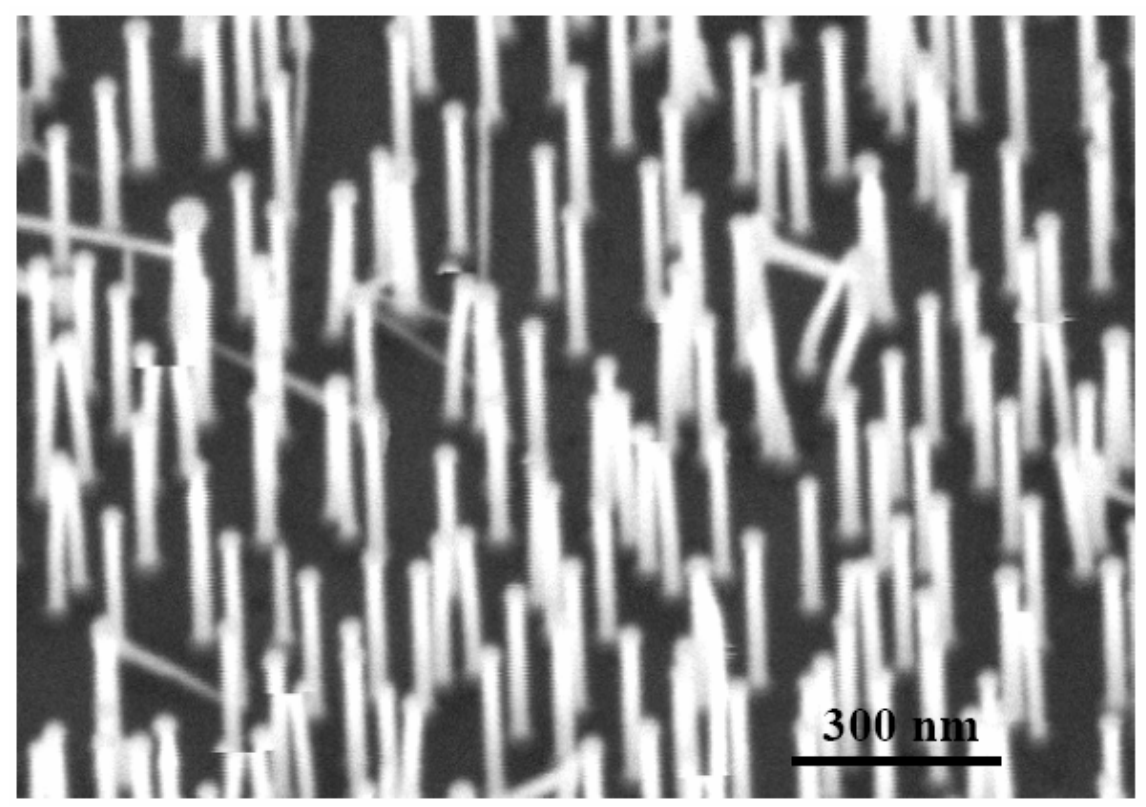

Fig. 10. Aligned $\mathrm{ZnO}$ nanorods/nanowires epitaxially grown on $\mathrm{ZnO}$ substrate using $\mathrm{Sn}$ as a catalyst [Gao et. al; Ref 15]

\section{ZnO nanowires properties and optical device applications}

$\mathrm{ZnO}$ exhibits a direct band-gap of $3.37 \mathrm{eV}$ at room temperature with large exciton energy of $60 \mathrm{meV}$. The strong exciton binding energy, which is much larger than that of GaN (25 $\mathrm{meV})$, and the thermal energy at room temperature $(26 \mathrm{meV})$ can ensure an efficient exciton emission at room temperature under low excitation energy. As a consequence, $\mathrm{ZnO}$ is recognized as a promising photonic material in the blue-UV region.

Single-crystalline $\mathrm{ZnO}$ nanowires have been synthesized using high temperature VLS growth methods discussed above [10,16]. Room temperature UV lasing in $\mathrm{ZnO}$ nanowires has been demonstrated [17]. PL spectra of the $\mathrm{ZnO}$ nanorods were measured with a fluorescence spectrophotometer using a Xe lamp with an excitation wavelength of $325 \mathrm{~nm}$ at room temperature. Figure 11 shows the PL spectrum of the $\mathrm{ZnO}$ nanorods with a diameter in the range $60 \pm 80 \mathrm{~nm}$. Three emitting bands, including a strong ultraviolet emission at around $386 \mathrm{~nm}$ and a very weak blue band $(440 \pm 480 \mathrm{~nm})$ as well as an almost negligible green band $(510 \pm 580 \mathrm{~nm})$, were observed.

The UV emission must be contributing to the near band edge emission of the wide band-gap $\mathrm{ZnO}$. It has been suggested that the green band emission corresponds to the singly ionized oxygen vacancy in $\mathrm{ZnO}$ and results from the recombination of a photo-generated hole with the singly ionized charge state of this defect. The stronger the intensity of the green luminescence, the more singly ionized oxygen vacancies there are. Thus the almost negligible green band in figure 11 shows that there is a very low concentration of oxygen vacancies in the well-aligned $\mathrm{ZnO}$ nanorods. The observation of blue band emission (440 \pm $480 \mathrm{~nm}$ ) of $\mathrm{ZnO}$ film has also been reported, using cathodoluminescence. 

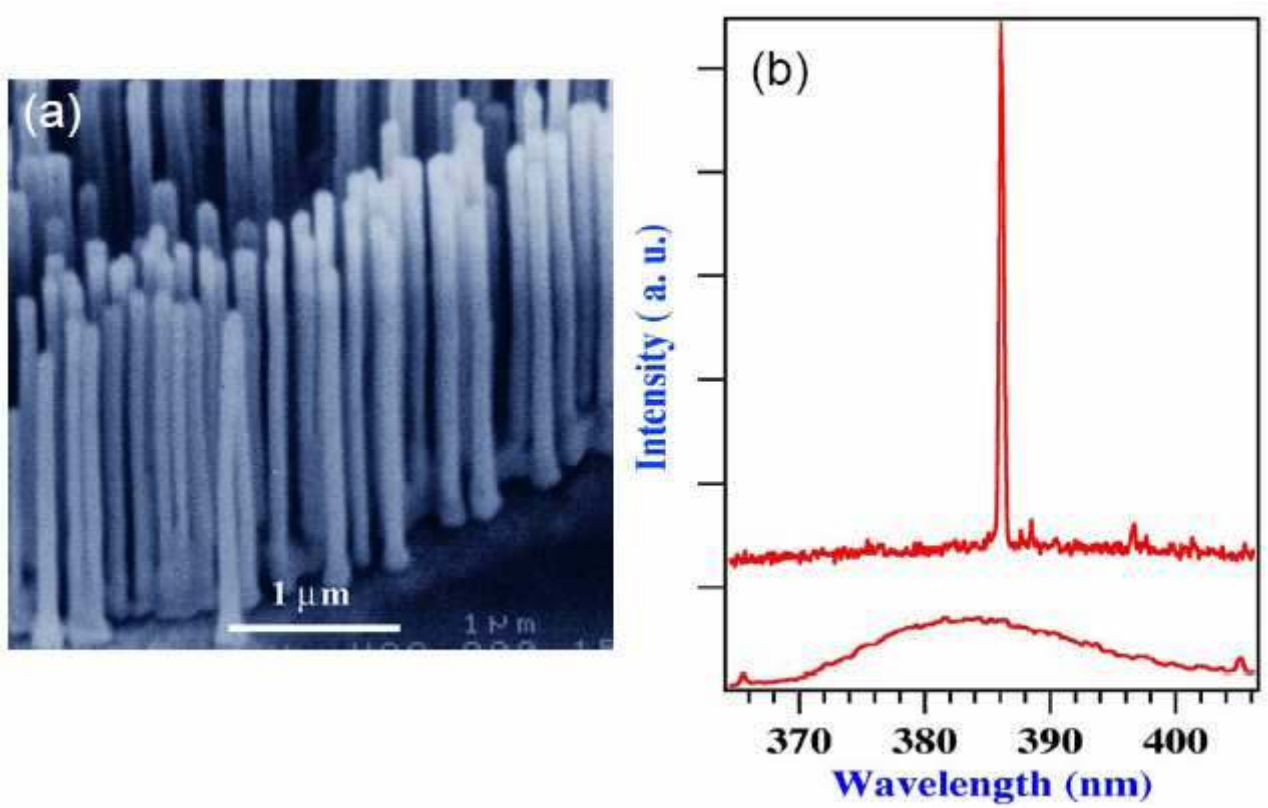

Fig. 11. (a) An SEM image of aligned $\mathrm{ZnO}$ nanowire arrays grown on sapphire substrate coated with a $3 \mathrm{~nm}$ thick layer of Au. (b) Emission spectra from nanowire arrays at pump powers of 20 and $100 \mathrm{~kW} \mathrm{~cm} \mathrm{-2.} \mathrm{The} \mathrm{spectra} \mathrm{are} \mathrm{offset} \mathrm{for} \mathrm{easy} \mathrm{comparison.} \mathrm{Stimulated}$ emission from the nanowires was collected in the direction along the nanowire end-plane normal (the symmetric axis) with a monochromator. All experiments were carried out at room temperature [P.D, Yang et al.; Ref 17]

\section{ZnO nanowire field effect transistor}

Field effect transistors have been fabricated using individual nanobelts [18]. Large bundles of $\mathrm{ZnO}$ nanobelts were dispersed in ethanol by ultrasonication until mostly individual nanobelts were isolated. These ethanol dispersions were dried onto a $\mathrm{SiO}_{2} / \mathrm{Si}$ substrate for imaging by non-contact mode atomic force microscopy (AFM). Field effect transistors were fabricated by depositing dispersed $\mathrm{ZnO}$ nanobelts on predefined gold electrode arrays. The $\mathrm{SiO}_{2}$ gate dielectric thickness was $120 \mathrm{~nm}$ and the back gate electrode was fabricated by evaporation of gold on the $\mathrm{Si}(\mathrm{p}+)$ side of the substrate.

In addition, in both fabrication schemes, the electrode arrays were variably spaced. They included electrode gaps as small as $100 \mathrm{~nm}$ and as large as $6 \mu \mathrm{m}$. An AFM image of the field effect transistor (FET) and a schematic diagram are shown in figure 12. The principle of this device is that controlling the gate voltage would control the current flowing from the source to the drain.

By forming metal electrode/nanostructure electrical contacts and capacitively coupling the nanostructure to a nearby gate electrode, an FET is produced using a nanobelt that allows the exploration of new aspects of the physical and chemical properties of the nanostructures $[19,20.21]$. 


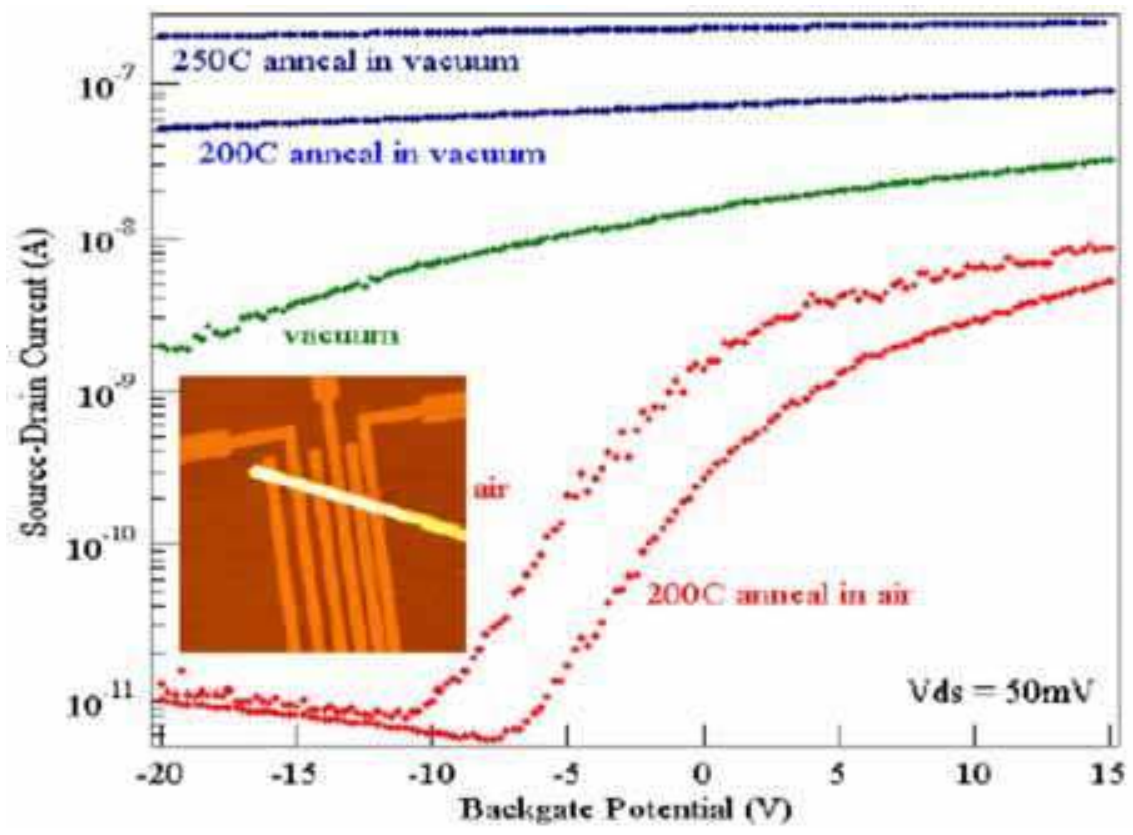

Fig. 12. ZnO nanobelt FET. Source-drain current versus gate bias for a $\mathrm{SnO}_{2} \mathrm{FET}$ after various treatments measured in this order: air, vacuum, $200 \mathrm{C}$ vacuum anneal, $250 \mathrm{C}$ vacuum anneal, $200 \mathrm{C}$ air anneal. The inset shows a field effect transistor (FET) device made using a single nanobelt. [Wang et al; Ref 22]

The alternative way of contacting the nanobelts by simply depositing them on top of prefabricated gold electrodes led to very resistive contacts. A typical $\mathrm{ZnO}$ field effect transistor showed a gate threshold voltage of $-15 \mathrm{~V}$, a switching ratio of nearly 100 and a peak conductivity of $1.25 \times 10^{-3} \Omega \mathrm{cm}^{-1}$. A completely analogous behavior has been observed in the case of carbon nanotubes deposited on top of Au electrodes or covered by Ti electrodes [22].

\section{UV photoconductivity measurements on $\mathrm{ZnO}$ nanostructures}

Ultraviolet light irradiation of the nanobelt diode of $\mathrm{ZnO}$ in air is observed to result in a significant increase of the conductivity [Figure. 13]. Light with a wavelength of $350 \mathrm{~nm}\left(E_{\lambda}=\right.$ $3.54 \mathrm{eV}$ ) was used, exceeding the direct band-gap of $\mathrm{ZnO}$. The increase in the conductivity results from both photo- generation of electron-hole pairs as well as doping by UV lightinduced surface desorption. These processes could be observed by introducing a shutter between the light source and the $\mathrm{ZnO}$ nanobelt so that the flux of UV photons could be turned 'ON' and 'OFF'.

The unique geometrical shape of nanobelts is ideal for field emission. $\mathrm{MoO}_{3}$ nanobelts have been shown to exhibit superior performance. The work function at the tips of individual $\mathrm{ZnO}$ nanobelts has been measured by a novel technique [23]. 


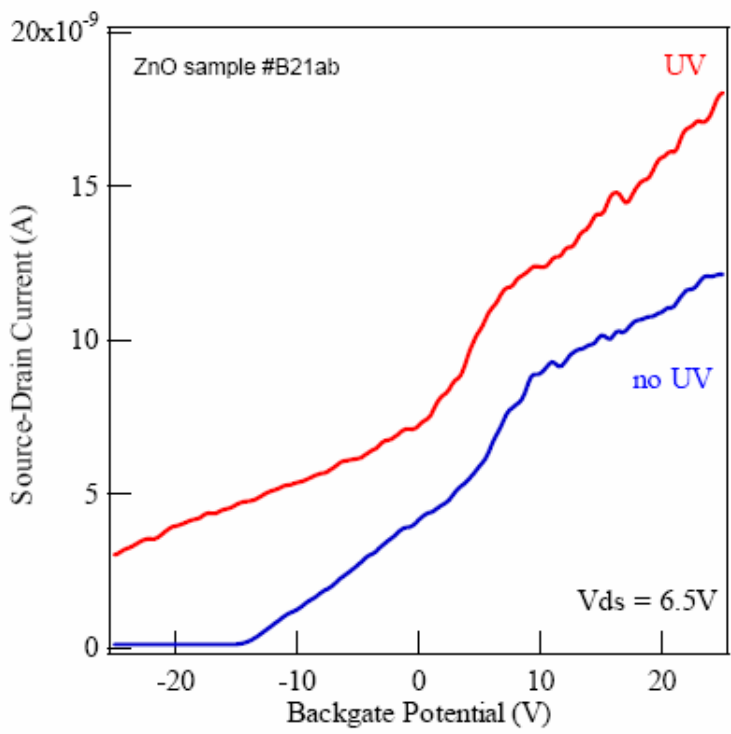

Fig. 13. Source-drain current measured from a $\mathrm{ZnO}$ nanobelt FET, showing a strong dependence on UV illumination [Wang et al; Ref 22]

\section{ZnO nanowire piezoelectric nanogenerator}

Wireless devices may allow in-situ, real-time biomedical monitoring and detection, but such devices still requires a power source. Ideally, such devices should be self-powered rather use a battery. The body provides numerous potential power sources - mechanical energy, vibrational energy, chemical energy (glucose), and hydraulic energy, but the challenge is their efficient conversion into electric energy. If accomplished on the nanoscale such power sources could have greatly reduced the size of the integrated nanosystems for optoelectronics [24], biosensors [25], resonators [26] and more. They have demonstrated an approach of converting mechanical energy into electric power using aligned $\mathrm{ZnO}$ NWs [27]. Their study is based on aligned $\mathrm{ZnO} N W$ s grown on c-plane oriented $-\mathrm{Al}_{2} \mathrm{O}_{3}$ substrate covered by a layer of $\mathrm{ZnO}$ film (Figure $14 \mathrm{a}$ ). The measurements were performed by AFM using a Si tip coated with Pt film. In the AFM contact mode, a constant normal force of $5 \mathrm{nN}$ was maintained between the tip and sample surface. The tip scanned over the top of the ZnO NW, and the tip's height was adjusted according to the surface morphology and local contacting force. The output voltage across an outside load of resistance $R_{L}=500 \mathrm{M} \Omega$ was continuously monitored as the tip scans over the NWs (note the defined polarity of the voltage signal) (Figure 14b). No external voltage was applied in any stage of the experiment. Experimentally, both the topography (feedback signal from the scanner) and the corresponding output voltage $\left(V_{L}\right)$ images across the load were recorded simultaneously when the AFM tip was scanned over the aligned NW arrays. In the voltage output image, many sharp output peaks (like discharge peaks) were observed, which are typically about 4 to 50 times higher than the noise level (Figure 14c). The location of the voltage peak is directly registered at the site of the NW. 


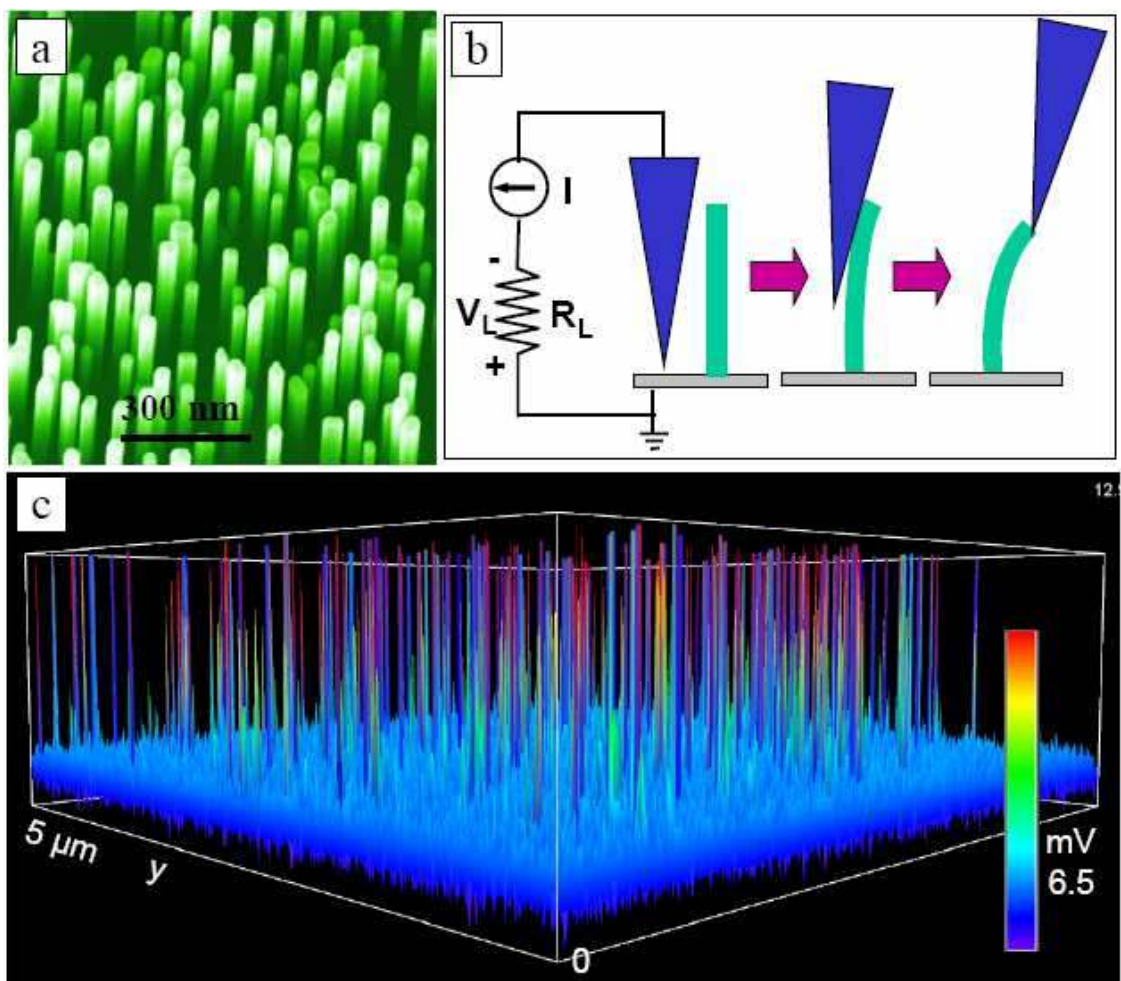

Fig. 14. (a) SEM images of aligned $\mathrm{ZnO}$ NWs grown on $\alpha-\mathrm{Al}_{2} \mathrm{O}_{3}$ substrate. (b) Experimental set up and procedures for generating electricity by deforming a piezoelectric NW using a conductive AFM tip. The root of the NW is grounded, and an external load of $R_{L}=500 \mathrm{M} \Omega$ is applied, which is much larger than the inner resistance $R_{I}$ of the NW. The AFM scans across the NW arrays in contact mode. (c) Output voltage image of the NW arrays when the AFM tip scans across the NW arrays. The discharging process is so quick that each discharge event is characterized by only a couple of data points. This gives a difficulty of displaying the data by rainbow color. [Wang et al; Ref 27]

The physical principle for creating, separating and preserving the PZ charges in the NW is a coupling of piezoelectric (PZ) and semiconducting properties [27, 28]. For a vertical, straight ZnO NW (Figures 15a), the deflection of the NW by AFM tip creates a strain field, with the outer surface being stretched (positive strain) and inner surface compressed (negative strain) (Figures 15b).

An electric field $E_{z}$ along the NW (z direction) is then created inside the NW volume through the PZ effect, $E_{z}={ }_{z} / d$, where $d$ is the PZ coefficient[29] along the NW direction that is normally the positive c-axis of $\mathrm{ZnO}$, with the $\mathrm{Zn}$ atomic layer being the front terminating layer [30]. The PZ field direction is closely parallel to the z-axis (NW direction) at the outer surface and anti-parallel to the z-axis at the inner surface (Figures 15c). Under the first-order approximation, across the width of the NW at the top end, the electric potential distribution from the compressed to the stretched side surface is approximately between $V_{s}^{-}$(negative) to $V_{s}^{+}$(positive). 

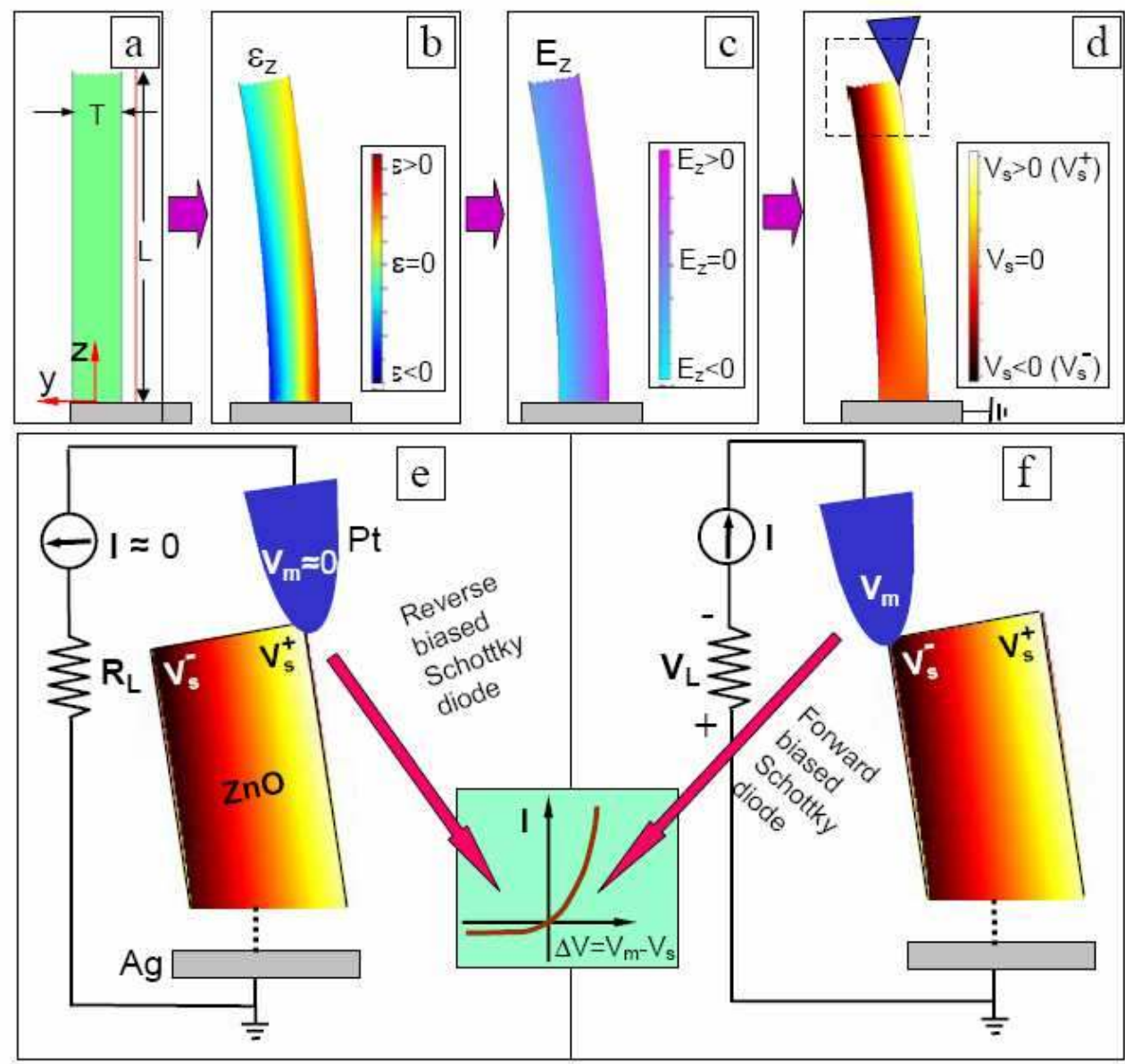

Fig. 15. Physical principle of the observed power generation process of a piezoelectric $\mathrm{ZnO}$ NW, showing a unique coupling of piezoelectric and semiconducting properties in this metal-semiconductor Schottky barrier governed transport process. (a) Schematic definition of a NW and the coordination system. (b) Longitudinal strain $\varepsilon_{z}$ distribution in the NW after being deflected by an AFM tip from the side. The data was simulated by FEMLAB for a ZnO NW of length $1 \mu \mathrm{m}$, aspect ratio of 10. (c) The corresponding longitudinal piezoelectric induced electric field $E_{z}$ distribution in the NW. (d) Potential distribution in the NW as a result of piezoelectric effect. The dashed box indicates the area to be examined in details in (e, f). (e, f) Metal and semiconductor contacts between the AFM tip and the semiconductor ZnO NW at two reversed local contact potentials (positive and negative), showing reverse and forward biased Schottky rectifying behavior, respectively (see text). It is this oppositely biased Schottky barrier across the NW makes it possible to preserve the piezoelectric charges and later produce the discharge output. Inset is a typical I-V characteristic of a metal-semiconductor (n-type) Schottky barrier. The process in (e) is built up the potential; the process in (f) is to discharge the potential. [Wang et al; Ref 27, 28] 
The electrode at the base of the NW is grounded. Note the $V_{s}^{+}$and $V_{s}^{-}$are the voltages produced by PZ effect, respectively. The potential is created by the relative displacement of the $\mathrm{Zn}^{2+}$ cations with respect to the $\mathrm{O}^{2-}$ anions due to $\mathrm{PZ}$ effect in the wurtzite crystal structure; thus, these ionic charges cannot freely move and cannot recombine without releasing the strain (Figures $15 \mathrm{~d}$ ). The potential difference is maintained as long as the deformation is in place and no foreign free charges (such as from the metal contacts) are injected.

We now consider the discharge process. In the first step, the AFM conductive tip that induces the deformation is in contact with the stretched surface of positive potential $V_{s}^{+}$(Figure $15 \mathrm{~d}$ and e). The $\mathrm{Pt}$ metal tip has a potential of nearly zero, $V_{m}=0$, so the metal tip - ZnO interface is negatively biased for $V=V_{m}-V_{s}^{+}<0$. With consideration the n-type semiconductor characteristic of the as-synthesized $\mathrm{ZnO} N W s$, the Pt metal- $\mathrm{ZnO}$ semiconductor (M-S) interface in this case is a reverse-biased Schottky diode (Fig. 40e), and little current flows across the interface. In the second step, when the AFM tip is in contact with the compressed side of the NW (Figure 415f), the metal tip - ZnO interface is positively biased for $V=V_{L}=V_{m}-V_{s}^{-}>0$.

The M-S interface in this case is a positively biased Schottky diode, and it produces a sudden increase in the output electric current. The current is the result of $V$ driven flow of electrons from the semiconductor $\mathrm{ZnO} \mathrm{NW}$ to the metal tip. The flow of the free electrons from the loop through the NW to the tip will neutralize the ionic charges distributed in the volume of the NW and thus reduce the magnitudes of the potential $V_{s}^{-}$and $V_{s}^{+}$.

The principle and technology demonstrated here have the potential of converting mechanical movement energy (such as body movement, muscle stretching, blood pressure), vibration energy (such as acoustic/ultrasonic wave) [74], and hydraulic energy (such as flow of body fluid, blood flow, contraction of blood vessel, dynamic fluid in nature) into electric energy that may be sufficient for self-powering nanodevices and nanosystems.

The technology could have important applications in wireless self-powered nanodevices by harvesting energy from the environment. It also provides a method for indirectly charging of a battery. It is also possible to fabricate large-power output electric generator by using arrays of $\mathrm{ZnO}$ wires/belts, which can be grown on substrates such as metal foils, flexible organic plastic substrates [31], ceramic substrates (such as alumina) and compound semiconductors (such as GaN and AlN). The nano-generator could be the basis for exploring new self-powering technology for in-situ, real-time and implantable Biosensing, biomedical monitoring and biodetection. It could have the potential of solving key energy requirement for remote sensing and actuating.

\section{Ultrasonic wave driven nanogenerators using $\mathrm{ZnO}$ nanowires}

For practical applications, we must make an innovative design to drastically improve the performance of the Nanogenerators in following aspects. First, we must eliminate the use of AFM for making the mechanical deformation of the NWs so that the power generation can be achieved by an adaptable, mobile and cost-effective approach over a larger scale. Secondly, all of the NWs are required to generate electricity simultaneously and continuously, and all the electricity can be effectively collected and output. 
Finally, the energy to be converted into electricity has to be provided in a form of wave/vibration from the environment, so the nanogenerator can operate "independently" and wirelessly. An innovative approach has been developed by Wang's group to use ultrasonic waves to drive a nanogenerator built from an array of vertically aligned $\mathrm{ZnO}$ NWs [32,33]. The design is novel and cost-effective and has the potential to meet the requirements outlined above. The approach is the basic platform for optimizing and improving the performance of the nanogenerator for its applications in nanotechnology.

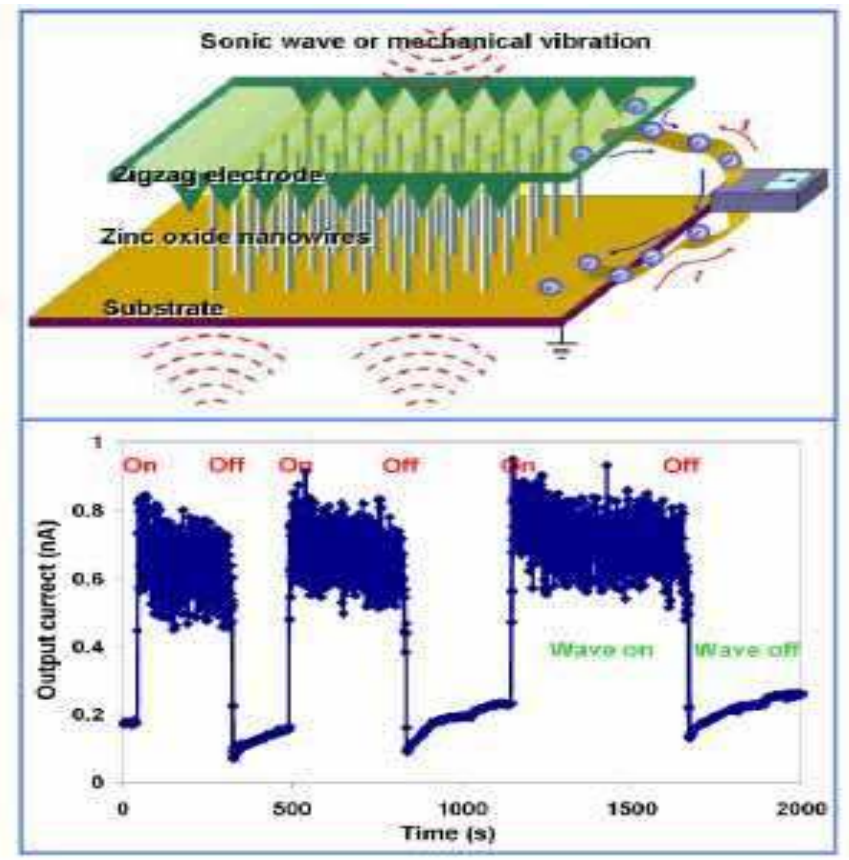

Fig. 16. Schematic diagram showing the direct current nanogenerator built using aligned $\mathrm{ZnO}$ nanowire arrays with a Zigzag top electrode. The nanogenerator is driven by an external ultrasonic wave or mechanical vibration and the output current is continuous. The lower plot is the output from a nanogenerator when the ultrasonic wave was on and off. The nanowire that simultaneously contributed to the DC current was estimated about 500

The experimental set up is schematically shown in Figure 16, in which an array of aligned $\mathrm{ZnO}$ NWs is covered by a zigzag Si electrode coated with Pt. The Pt coating is not only for enhancing the conductivity of the electrode but also for creating a Schottky contact at the interface with $\mathrm{ZnO}$. The NWs were grown on either $\mathrm{GaN}$ substrates, which served as a common electrode for directly connecting with an external circuit. The asymmetric piezoelectric-potential across the width of a $\mathrm{ZnO} \mathrm{NW}$ and the Schottky contact between the metal electrode and the NW are the two key processes for creating, separating, preserving/accumulating, and outputting the charges.

A top electrode is designed to achieve the coupling process and to replace the role played by the AFM tip, and its zigzag trenches are to act as an array of aligned AFM tips. The DC nanogenerator is driven by ultrasonic wave. Once the wave is on, about 500 nanowires 
within an area of $2 \mathrm{~mm}^{2}$ gives $1 \mathrm{nA} \mathrm{DC}$ current. We propose to fabricate a nanogenerator that is expected to output the electricity generated by all of the nanowires continuously.

\section{Thin film and nanostructure solar cells}

$\mathrm{ZnO}$ thin films and nanostructures are being developed for design and development of high efficiency solar cells $[34,35,36]$. The use of $\mathrm{ZnO}$ thin films and nanostructures in solar cells will provide an inexpensive option for large area solar cells. The Zinc oxide nanorods are attractive for photo-voltaic applications and this claim is based on their properties. Typical $\mathrm{ZnO}$ nanorods have a wurtzite structure with lattice spacing $\mathrm{a}=0.32469 \mathrm{~nm}$ and $\mathrm{c}=0.52069$ nm [37].

Significant progress has been made in thin film solar cells that have demonstrated efficiency in excess of 30 percent for GaAs based multijunction solar cells, which are being used for space mission [39]. There are several different configurations that would allow high efficiency solar cells. More recently, there is interest in using GaN / InGaN and $\mathrm{ZnO} /$ $\mathrm{MgZnO}$ for development of high efficiency multijunction solar cells [40].

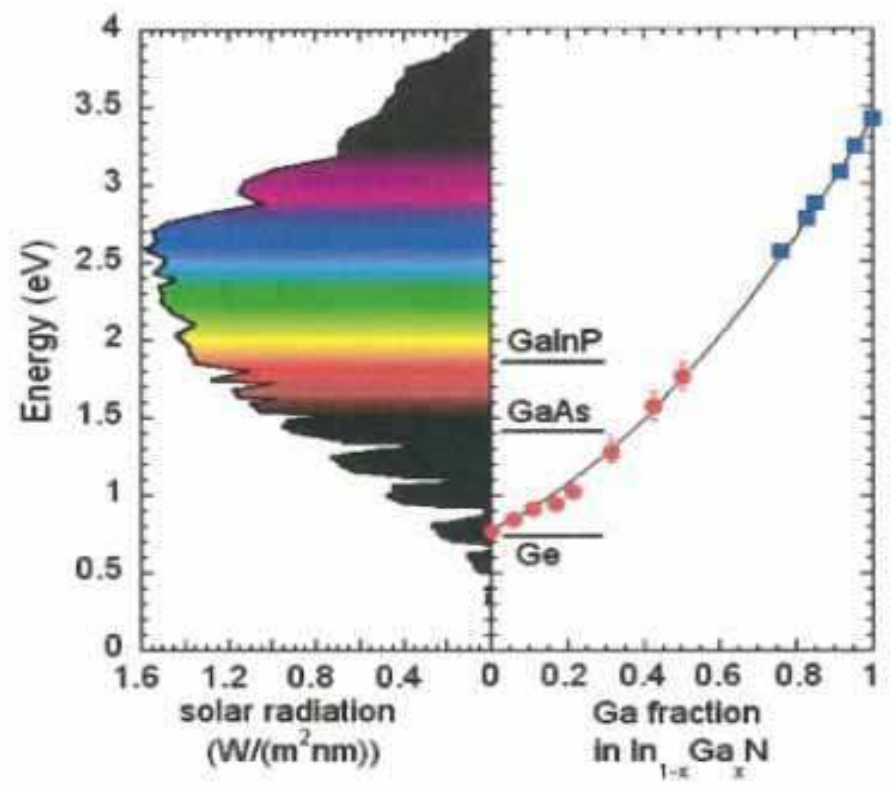

Fig. 17. Band gap energy for solar spectrum. Several material systems are being developed to provide high efficiency multijunction solar cells. These include material components Ge, GaAs and GaInP, InGaN and ZnO. [Wu et al; Reference 40]

Figure 17 presents complete solar spectrum for AM-1.5 solar cells. Different material systems can be utilized to accomplish high efficiency multijunction solar cells. Most of the multijunction solar cells have been developed for space missions where availability of high efficiency is of paramount importance and issue of radiation hardness is critical success for the space missions. There has been significant effort for development of low cost technologies that will allow high efficiency thin film solar cells for terrestrial applications. 
$\mathrm{ZnO}$ is being explored as one of the key components for a variety of low cost thin film and nanostructure based solar cells. Recent work reported by Ganguly and his coworkers [41] has explored the use of amorphous silicon solar cells with $\mathrm{ZnO}$ with insertion of Germanium layers. They have shown that with insertion of a thin amorphous germanium layer at the ZnO-p-layer interface improves the cell performance and diode ideality by suppression of Oxygen and Zinc incorporation in the silicon layers. One of the advantages of $\mathrm{ZnO}$ is is its resistance to hydrogen plasma induced darkening and higher transmission thereby improving the solar cell efficiency.

Recent work by Peiro and his coworkers [36] at Imperial college and Manchester in UK have shown that solar cells fabricated from composites of conjugated polymers with nanostructure $\mathrm{ZnO}$ are of great interest for their stability, low cost and electron transport properties. ZnO polymer solar cells are promising for low temperature synthesis.

Zinc oxide $(\mathrm{ZnO}) /$ polymer solar cells are promising compared to other metal oxide/polymer combinations, on account of the possibility of low temperature synthesis, as well as the potential for controlling interface morphology through simple processing from solution. They have focused on the effect of surface morphology of $\mathrm{ZnO}$ films on photovoltaic device performance. They have successfully grown $\mathrm{ZnO}$ nanorods standing almost perpendicular to the electrodes on a flat, dense $\mathrm{ZnO}$ "backing" layer.

They have studied [ 36,37$]$ structures consisting of a conjugated polymer in contact with three different types of $\mathrm{ZnO}$ layer: a flat $\mathrm{ZnO}$ backing layer alone; $\mathrm{ZnO}$ nanorods on a $\mathrm{ZnO}$ backing layer; and $\mathrm{ZnO}$ nanoparticles on a $\mathrm{ZnO}$ backing layer. They also used scanning electron microscopy, steady state and transient absorption spectroscopy and photovoltaic device measurements to study the morphology, charge separation and recombination behavior and device performance of the three types of structures.

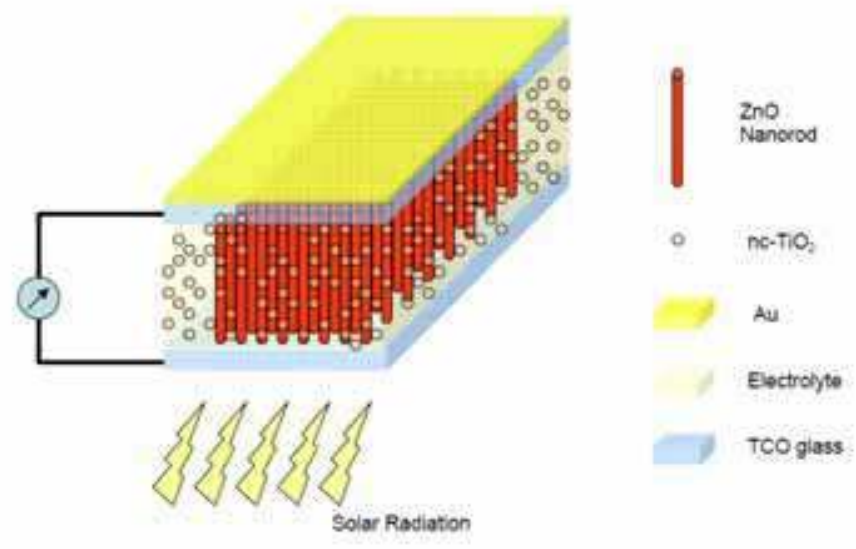

Fig. 18. Schematic diagram of $\mathrm{ZnO}$ based nanostructure solar cell [Sridhar et al; Ref 34]

They found that charge recombination in the structures containing vertically aligned $\mathrm{ZnO}$ nanorods is remarkably slow, with a half life of over $1 \mathrm{~ms}$, over two orders of magnitude slower than for randomly oriented $\mathrm{ZnO}$ nanoparticles. A photovoltaic device based on the nanorods structure which has been treated with an ambiphilic dye before deposition of poly(3-hexyl thiophene) (P3HT) polymer shows a power conversion efficiency over four times greater than for a similar device based on the nanoparticles structure. 
The best $\mathrm{ZnO}$ nanorods: P3HT device yields a short circuit current density of $2 \mathrm{mAcm}-2$ under AM1.5 illumination (100mWcm-2) and peak external quantum efficiency over $14 \%$, resulting in a power conversion efficiency of $0.20 \%$. Their effort demonstrates the potential of $\mathrm{ZnO}$ nanostructure based solar cells have the potential of low cost and further improvements can yield higher efficiency solar cells.

Several other groups in US, China and England [34, 36, 41, 42] are working on ZnO nanostructure solar cells. They are all trying to develop the necessary understanding for growth and characterization of $\mathrm{ZnO}$ nanostructures on variety of substrates.

Investigation of $\mathrm{ZnO}$ nanorods based solar cells is being conducted towards developing alternative, lightweight, flexible devices for commercial applications. A schematic view is shown in figure 18.A lot of research has been done in the area of dye sensitized solar cells [ 37, 42] in particular, which is currently the most stable and efficient excitonic solar cell. Aligned $\mathrm{ZnO}$ nanorods, with their high carrier mobilities serve as the conduction pathways for the excitons. These approaches provide a glimpse of what is being done on using $\mathrm{ZnO}$ nanostructures fro solar cell applications. Further effort is needed in developing $\mathrm{ZnO}$ based solar cells that can be implemented in terrestrial applications.

\section{UV atmospheric transmission model}

There has been recent effort to study the atmospheric transmission models in UV, Visible and Infrared (IR) bands [43]. Modeling of atmospheric effects on transmission at UV wavelengths (250-350 $\mathrm{nm}$ range) was performed using MODTRAN. MODTRAN (MODerate resolution atmospheric TRANsmission) is an atmospheric radiative transfer model that may be used to determine the effects of various atmospheric layers and weather conditions on wavelength dependent free-space transmission. Six different atmospheric models were simulated: clear maritime ( $23 \mathrm{~km}$ visibility), desert extinction, drizzle (2 $\mathrm{mm} / \mathrm{hr})$, light rain $(5 \mathrm{~mm} / \mathrm{hr})$, moderate rain $(12.5 \mathrm{~mm} / \mathrm{hr})$, and heavy rain $(25 \mathrm{~mm} / \mathrm{hr})$.

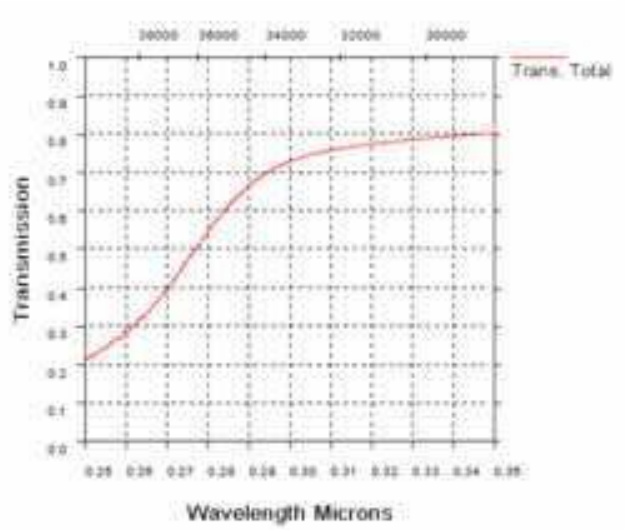

(a)

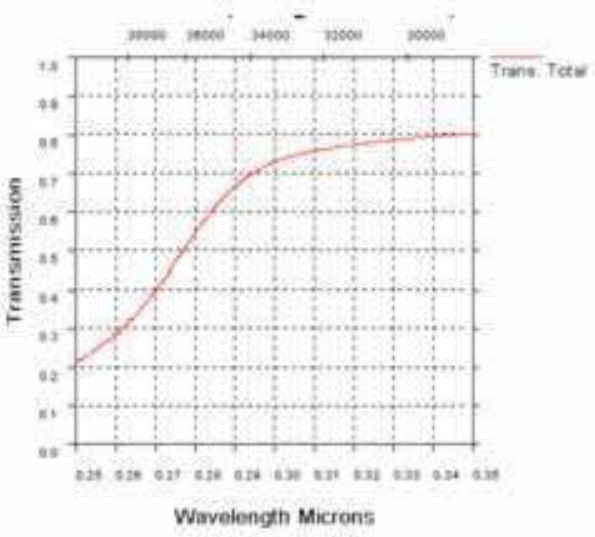

(b)

Fig. 19. UV atmospheric transmission over a horizontal path in clear maritime $(23 \mathrm{~km}$ visibility) conditions, $1 \mathrm{~km}$ range (19 a). UV transmission through atmosphere over a horizontal path in desert extinction conditions, $1 \mathrm{~km}$ range $(19 \mathrm{~b})$ 
For each of these weather conditions, UV transmission was modeled for $1 \mathrm{~km}$ horizontal paths through the atmosphere $5 \mathrm{~m}$ above the surface (Figures 1-6). In addition, slanted paths at angles of $15^{\circ}, 30^{\circ}, 45^{\circ}$, and $60^{\circ}$ from the horizon for a distance of $10 \mathrm{~km}$ were simulated in clear maritime conditions (Figures 19-23) to show the relative effects of propagation though different lower atmospheric layers on attenuation. In relation to freespace optical communication networks, a $0^{\circ}$ horizontal path would involve ground based communication extending no further than the horizon, while an upward slanted path might involve communication between a ground-based unit or sea vessel and an aircraft [43].

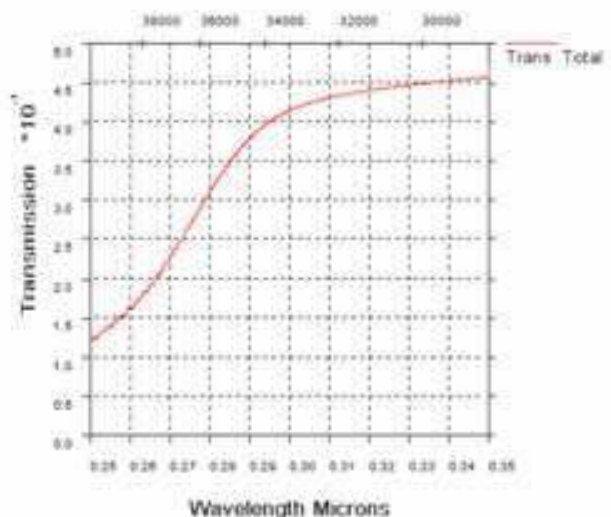

(a)

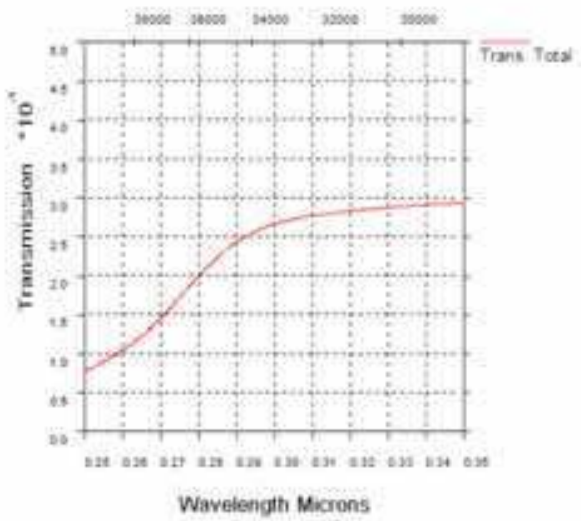

(b)

Fig. 20. UV atmospheric transmission over a horizontal path in drizzle $(2 \mathrm{~mm} / \mathrm{hr})$ conditions, $1 \mathrm{~km}$ range (20a) and UV transmission over a horizontal path in light rain (5 $\mathrm{mm} / \mathrm{hr}$ ) conditions, $1 \mathrm{~km}$ range $(20 \mathrm{~b})$.

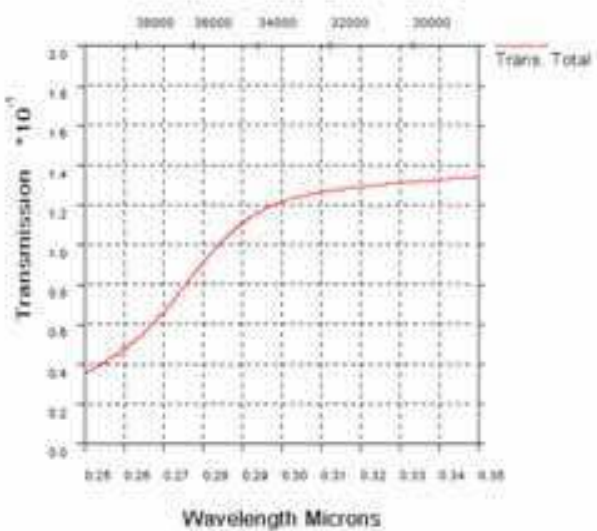

(a)

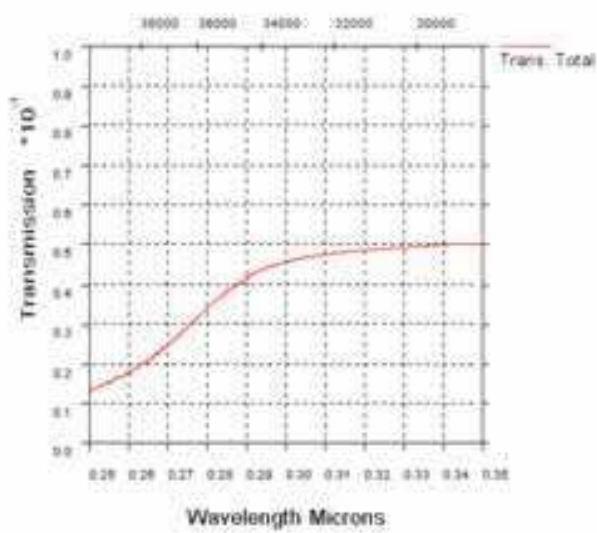

(b)

Fig. 21. UV transmission through atmosphere over a horizontal path in moderate rain (12.5 $\mathrm{mm} / \mathrm{hr}$ ) conditions, $1 \mathrm{~km}$ range (21a). UV transmission over a horizontal path in heavy rain (25 $\mathrm{mm} / \mathrm{hr}$ ) conditions, $1 \mathrm{~km}$ range $(21 \mathrm{~b})$ 


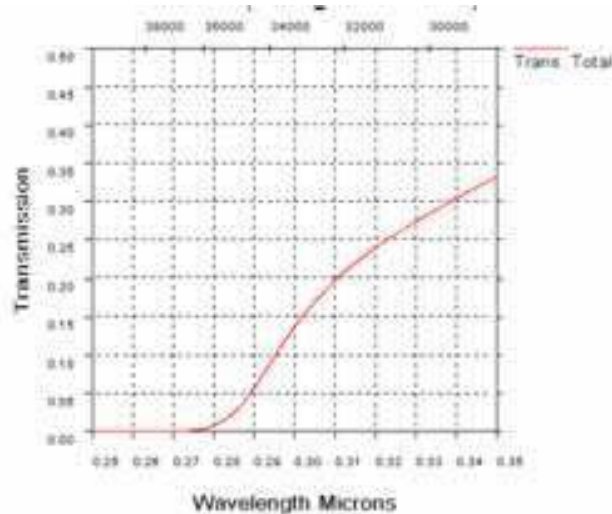

(a)

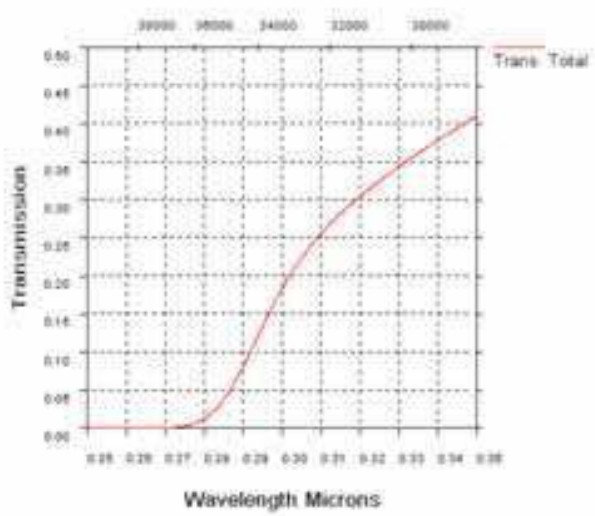

(b)

Fig. 22. UV atmospheric transmission over a slanted path at $15^{\circ}$ elevation in clear maritime conditions, $10 \mathrm{~km}$ range (22a). UV transmission over a slanted path at $30^{\circ}$ elevation in clear maritime conditions, $10 \mathrm{~km}$ range $(22 \mathrm{~b})$

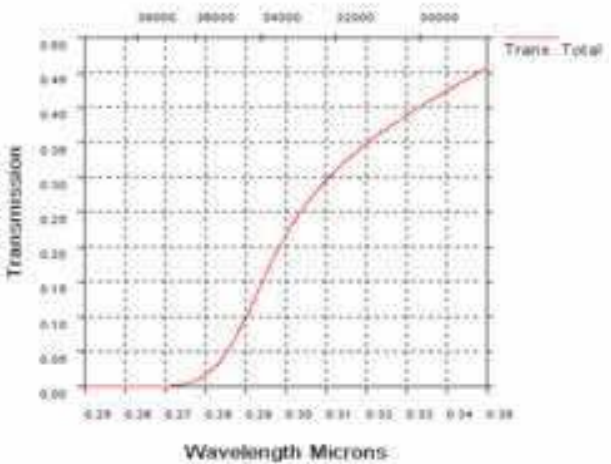

(a)

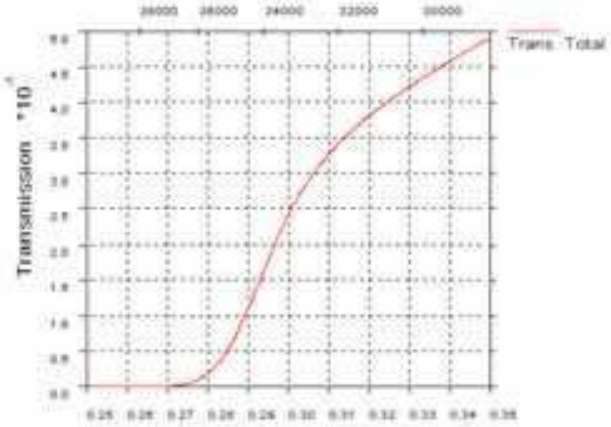

Wavelongth Microns:

(b)

Fig. 23. UV transmission over a slanted path at $45^{\circ}$ elevation in clear maritime conditions, 10 $\mathrm{km}$ range (23a). UV atmospheric transmission over a slanted path at $60^{\circ}$ elevation in clear maritime conditions, $10 \mathrm{~km}$ range ( $23 \mathrm{~b}$ )

\section{Summary}

In this chapter, we have discussed growth, fabrication and characterization of $\mathrm{ZnO}$ nanostructures materials and devices on a variety of substrates. $\mathrm{ZnO}$ nanostructures offer potential for a variety of optical, electronic and biological devices for nanoscale applications. The Zinc oxide nanostructures are also attractive for energy generation devices and photovoltaic applications. Significant research effort is underway on $\mathrm{ZnO}$ nanostructures, their unique properties for application in transparent electronics, ultraviolet (UV) light emitters, piezoelectric devices, chemical sensors and spin electronics. 
An assortment of $\mathrm{ZnO}$ nanostructures, such as nanorods, nanotubes and nanorings, have been successfully grown via a variety of methods including chemical vapor deposition, thermal evaporation, hydrothermal technique, sol-gel and electro-deposition. These nanostructures have been evaluated for electronic devices, UV detectors, light emitting diodes, lasers, gas sensors, and other biological applications. Further work is underway that will enhance our understanding of $\mathrm{ZnO}$ nanostructures and their applications for future system applications.

\section{Acknowledgement}

The authors would like to acknowledge the contributions of many students at Georgia Tech that have over the years contributed to the exciting work, which has been published by them and presented here in the chapter. We would also like to acknowledge the modeling effort by Dr. John Zeller of NUWC, Newport, RI. The authors would also like to acknowledge the financial support by numerous agencies that have contributed to the $\mathrm{ZnO}$ nanostructures and their applications.

\section{References}

[1] J. R. Choi and Dennis. L. Polla eburnal of Micromechanical Micro-engineering Volume 3, 6064, 1993

[2] E. J. Egerton, A. K. Sood, R. Singh, Y. R. Puri, R. F. Davis, J. Pierce, D. C. Look and T. Steiner, eburnal of Electronic Materials Vol.34, No.6, 2005

[3] Z. L. Wang, A Review Paper, eburnal of Physics: Condensed Matter 16, 829-858, 2004

[4] X. Wang, J. Song, C. J. Summers, J. H. Ryou, P. Li, R. D. Dupuis, and Z. L. Wang , I Phys. Chem. B, 110 (2006) 7720-7724

[5] X. Wang , J. Song , P. Li , J. H. Ryou, R. D. Dupuis , C. J. Summers and Z. L. Wang , el Am. Chem. Soc., 127 (2005) 7920-7923

[6] X. Wang, C. J. Summers and Z. L. Wang, Nano Letters, 3 (2004) 423-426.

[7] Z. L. Wang and J. Song, Science, 312 (2006) 242-246

[8] Z. Fan and J.G. Lu, eburnal of Nanoscience and Nanotechnology, Volume 5, 1561-1573 (2003)

[9] R.S. Yang, Y. Ding and Z.L. Wang, Nano Lett., 4, 1309 (2004)

[10] A.K. Sood, Y.R. Puri, P. Gao, C. Lao, Z.L. Wang, D.L. Polla, M.B. Soprano, Proceedings of SPIE, Volume 6556, 6556IL ( 2007)

[11] L. Luo, B. Sosnowchik and L.W. Lin, Applied Physics Letters 90, 093101 (2007)

[12] W. Lee, M. C. Jeong and J.M. Myoung, Acta Materialia, 52, 3949-3957(2004)

[13] J. B. Baxter and E.S. Aydil, eburnal of Electrochemical Society, 156 (1), H52-H58 (2009)

[14] P. X. Gao and Z. L. Wang, el Phys. Chem. B 106, 12653 (2002)

[15] P. X. Gao, Y. Ding and Z. L. Wang, Nano Lett. 3, 1315 (2003)

[16] Z. W. Pan, Z. R. Dai and Z. L. Wang, Science 291, 1947(2001)

[17] M. H. Huang, Y. Y. Wu, H. Feick, N. Tran, E. Weber and P. D. Yang, Adv. Mater. 13, 113 (2001)

[18] M. S. Arnold, P.H. Avouris, Z. W. Pan and Z. L. Wang, el Phys. Chem. B 107, 659 (2003)

[19] Y. Cui and C. M. Lieber, Science 291, 851 (2001)

[20] P. G. Collins, M. S. Arnold and Ph. Avouris, Science 292, 706 (2001)

[21] J. Kong, N. Franklin, C. Wu, S. Pan, K. J. Cho and H. Dai, Science 287, 622 (2000)

[22] Wang, X.D., Ding, Y. Summers, C.J. and Wang, Z.L., el Phys. Chem. B. 108, 8773 (2004) 
[23] X. Bai, E. G. Wang, P. Gao and Z. L. Wang, NanoLetters, 3, 1147 (2003)

[24] P. M. Morales and C. M. Lieber, Science 279, 208 (1998)

[25] G.F. Zheng, F. Patolsky, Y. Cui, W.U. Wang, and C.M. Lieber, Nature Biotechnology 23 (2005) p. 1294

[26] X.D. Bai, P.X. Gao, Z.L. Wang and E.G. Wang, Appl. Phys. Letts. 82, p. 4806 ( 2003 )

[27] Z. L. Wang, and J. H. Song, Science 312 , p. 242 ( 2006)

[28] J.H. Song, J. Zhou, and Z.L. Wang, Nano Lett. 6 p. 1656 ( 2006)

[29] M.H. Zhao, Z.L. Wang, and S.X. Mao, Nano Lett. 4 (2004) p. 587

[30] Z.L. Wang, X.Y. Kong, and J.M. Zuo, Phys. Rev. Letts. 91 (2003) p. 185502

[31] Z.L. Wang and J. H. Song, Science, 312 , 242-246 ( 2006)

[32] P.X. Gao, J.H. Song, J. Liu and Z.L. Wang, Advanced Materials, 19, 67-72 (2006)

[33] X.D. Wang, J.H. Song, J. Liu and Z.L. Wang, Science, 316, 102-105 ( 2007)

[34] D. Sridhar, J. Xie, J.K. Abraham, V. K. Varodan and S.H. Choi, Proceedings of SPIE, Volume 6172 ( 2006)

[35] W. J. F. Beck, L. H. Slooft, M. J. Wienk, J. M. Kroon, and R.A. J. Janssen, Proceedings of SPIE, Volume 5938 ( 2005)

[36] A. M. Piero, P. Ravirajan, K. Govender, D.S. Boyle, P.O. O'Brien, D.C. Bradley, J. Nelson and J.R. Durrant, Proceedings of SPIE, Volume 5938 ( 2005)

[37] J. R. Baxter and E.S. Aydil, Applied Physics Letters, 86, 053114 (2005)

[38] For Silicon Solar Cells, i.e. Evergreen Solar (Marlboro, MA), Schott Solar (Burlington, MA), and other Silicon Solar Cell Manufacturers). The cell efficiency varies from 1418 percent for Polysilicon to Single Crystal Silicon Solar Cells.

[39] T. Takamoto, E. Ikeda, H. Kurita and M. Ohmori, Applied Physics Letters, 70, 381 ( 1997)

[40] J. Wu, W. Walukiewicz, K. M. Yu, W. Shan, J. W. Ager, E.E. Haller, H. Lu, W.J. Schaff, W.K. Metzer and S. Kurtz, eburnal of Applied Physics, Volume 94, 6477 ( 2003)

[41] G. Ganguly, D.E. Carlson, S. S. Hyedus, D. Ryan , R. Gordon, D. Pang and R. C. Reedy, Applied Physics Letters 85, p 479 ( 2004)

[42] Z. Longyue, D. Songyuan, X. Weiwei and K. Wang, Plasma Science and Technology, Volume 8, No2, March 2006

[43] J. Zeller and T. Manzur, Proceedings of SPIE, Volume 7833, 783313 (2010) 


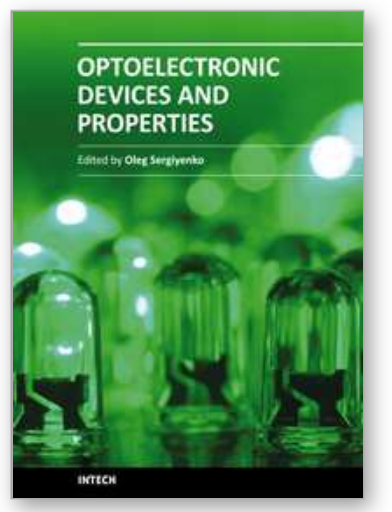

\section{Optoelectronic Devices and Properties}

Edited by Prof. Oleg Sergiyenko

ISBN 978-953-307-204-3

Hard cover, 660 pages

Publisher InTech

Published online 19, April, 2011

Published in print edition April, 2011

Optoelectronic devices impact many areas of society, from simple household appliances and multimedia systems to communications, computing, spatial scanning, optical monitoring, 3D measurements and medical instruments. This is the most complete book about optoelectromechanic systems and semiconductor optoelectronic devices; it provides an accessible, well-organized overview of optoelectronic devices and properties that emphasizes basic principles.

\section{How to reference}

In order to correctly reference this scholarly work, feel free to copy and paste the following:

Ashok K. Sood, Zhong Lin Wang, Dennis L. Polla, Nibir K. Dhar, Tariq Manzur and A.F.M. Anwar (2011). ZnO Nanostructures for Optoelectronic Applications, Optoelectronic Devices and Properties, Prof. Oleg Sergiyenko (Ed.), ISBN: 978-953-307-204-3, InTech, Available from: http://www.intechopen.com/books/optoelectronicdevices-and-properties/zno-nanostructures-for-optoelectronic-applications

\section{INTECH}

open science | open minds

\author{
InTech Europe \\ University Campus STeP Ri \\ Slavka Krautzeka 83/A \\ 51000 Rijeka, Croatia \\ Phone: +385 (51) 770447 \\ Fax: +385 (51) 686166 \\ www.intechopen.com
}

\author{
InTech China \\ Unit 405, Office Block, Hotel Equatorial Shanghai \\ No.65, Yan An Road (West), Shanghai, 200040, China \\ 中国上海市延安西路65号上海国际贵都大饭店办公楼 405 单元 \\ Phone: +86-21-62489820 \\ Fax: $+86-21-62489821$
}


(C) 2011 The Author(s). Licensee IntechOpen. This chapter is distributed under the terms of the Creative Commons Attribution-NonCommercialShareAlike-3.0 License, which permits use, distribution and reproduction for non-commercial purposes, provided the original is properly cited and derivative works building on this content are distributed under the same license. 